\title{
A new inhibitor of the $\beta$-arrestin/AP2 endocytic complex reveals interplay between GPCR internalization and signalling
}

Alexandre Beautrait ${ }^{1, \star}$, Justine S. Paradis ${ }^{2, \star}$, Brandon Zimmerman $^{3, \star}$, Jenna Giubilaro $^{3}$, Ljiljana Nikolajev ${ }^{4}$, Sylvain Armando ${ }^{4}$, Hiroyuki Kobayashi ${ }^{1}$, Lama Yamani ${ }^{4}$, Yoon Namkung ${ }^{4}$, Franziska M. Heydenreich ${ }^{5}$, Etienne Khoury ${ }^{4}$, Martin Audet', Philippe P. Roux ${ }^{6}$, Dmitry B. Veprintsev ${ }^{5}$, Stéphane A. Laporte $3,4,7$ $\&$ Michel Bouvier ${ }^{1}$

In addition to $G$ protein-coupled receptor (GPCR) desensitization and endocytosis, $\beta$-arrestin recruitment to ligand-stimulated GPCRs promotes non-canonical signalling cascades. Distinguishing the respective contributions of $\beta$-arrestin recruitment to the receptor and $\beta$-arrestin-promoted endocytosis in propagating receptor signalling has been limited by the lack of selective analytical tools. Here, using a combination of virtual screening and cell-based assays, we have identified a small molecule that selectively inhibits the interaction between $\beta$-arrestin and the $\beta 2$-adaptin subunit of the clathrin adaptor protein AP2 without interfering with the formation of receptor $/ \beta$-arrestin complexes. This selective $\beta$-arrestin/ $\beta 2$-adaptin inhibitor (Barbadin) blocks agonist-promoted endocytosis of the prototypical $\beta 2$-adrenergic $(\beta 2 A R), V 2$-vasopressin (V2R) and angiotensin-II type-1 (AT1R) receptors, but does not affect $\beta$-arrestin-independent (transferrin) or AP2-independent (endothelin-A) receptor internalization. Interestingly, Barbadin fully blocks V2R-stimulated ERK1/2 activation and blunts cAMP accumulation promoted by both $V 2 R$ and $\beta 2 A R$, supporting the concept of $\beta$-arrestin/AP2-dependent signalling for both $G$ protein-dependent and -independent pathways.

\footnotetext{
${ }^{1}$ Department of Biochemistry, Institute for Research in Immunology and Cancer (IRIC), Université de Montréal, Montréal, Quebec, Canada H3T 1J4.

${ }^{2}$ Department of Molecular Biology Program, Institute for Research in Immunology and Cancer (IRIC), Université de Montréal, Montréal, Quebec, Canada H3T 1J4. ${ }^{3}$ Department of Pharmacology and Therapeutics, Research Institute of McGill University Health Centre (RI-MUHC), McGill University, Montréal, Quebec, Canada H4A 3J1. ${ }^{4}$ Department of Medicine, Research Institute of McGill University Health Centre (RI-MUHC), McGill University, Montréal, Quebec, Canada H4A 3J1. ${ }^{5}$ Laboratory of Biomolecular Research, Department of Biology and Chemistry, Paul Scherrer Institut,5232 Villigen PSI, Switzerland, Switzerland. ${ }^{6}$ Department of Pathology and Cellular Biology, Institute of Research in Immunology and Cancer (IRIC), Université de Montréal, Montréal, Quebec, Canada H3T 1J4. ${ }^{7}$ Department of Anatomy and Cell Biology, Research Institute of McGill University Health Centre (RI-MUHC), McGill University, Montréal, Quebec, Canada H4A 3J1. * These authors contributed equally to this work. Correspondence and requests for materials should be addressed to S.A.L. (email: stephane.laporte@mcgill.ca) or to M.B. (email: michel.bouvier@umontreal.ca).
} 
B eta-arrestins ( $\beta$-arrestin1 and $\beta$-arrestin2) play central roles in the mechanisms regulating $G$ protein-coupled receptor (GPCR) signalling and trafficking ${ }^{1,2}$. The recruitment of $\beta$-arrestin to phosphorylated activated GPCRs at the plasma membrane, following sustained agonist stimulation, promotes desensitization by functionally uncoupling the activated receptors from their heterotrimeric $G$ proteins ${ }^{3}$. Complexes formed between ligand-occupied GPCRs and $\beta$-arrestin are then directed to the endocytic machinery, leading to their interaction with clathrin and its adaptor protein $\mathrm{AP} 2$, followed by the internalization of the receptors ${ }^{4-6}$. Once internalized and targeted to early endosomes, receptors can either be recycled back to the plasma membrane or targeted toward lysosomal degradation. The fate of the endocytosed receptors has been inferred to depend largely on the stability of the interaction between the internalized receptor and $\beta$-arrestin ${ }^{7}$; where the more labile complexes lead to rapid recycling of receptor, whereas more stable interactions prevent recycling and favour receptor degradation. Although endocytosis was first linked to receptor desensitization and resensitization, more recent evidence suggest that internalized receptors can engage in various signalling activities 8,9 . For instance, endocytosis has been linked to the $\beta$-arrestindependent activation of mitogen-activated protein kinases $(\mathrm{MAPK})^{10}$ and the sustained activation of adenylyl-cyclase by some receptors ${ }^{11-13}$. Despite the well-established contribution of $\beta$-arrestins in various steps of receptor trafficking and signalling, spatial and temporal causative links between these responses have remained difficult to probe, mainly because of the lack of selective pharmacological tools.

Several endocytic paths have been described for GPCRs, including both clathrin-dependent and -independent events ${ }^{14,15}$, with the vast majority of GPCRs undergoing $\beta$-arrestindependent, clathrin-mediated endocytosis. Upon binding to agonist-bound receptor, $\beta$-arrestin undergoes a major conformational change, adopting an active conformation that is characterized by the release of its C-terminus, which is buried in its polar core $\mathrm{c}^{16}$. The exposed $\beta$-arrestin $\mathrm{C}$-tail constitutes an accessible site (DxxFxxFxxxR motif) for the binding of the $\beta 2$-adaptin subunit of the AP2 complex, which directs the receptor/ $\beta$-arrestin complexes into maturing clathrin-coated pits $(\mathrm{CCPs})^{17,18}$. A tripartite interaction exists between $\beta$-arrestin, AP2 and clathrin in CCPs (that is, each protein involved in a direct interaction with the other two proteins) and the interaction between $\beta$-arrestin and AP2 is an important initial step in localizing GPCRs into the CCP, following agonist stimulation ${ }^{17}$. The structural determinants for $\beta$-arrestin and AP2 interaction have been well-defined ${ }^{17,19}$, and more recently validated by a co-crystal between the $\beta 2$-adaptin subunit of AP2 and a peptide fragment of $\beta$-arrestin1 C-terminus ${ }^{20}$. Most of our knowledge concerning GPCR endocytosis and $\beta$-arrestin-dependent signalling has been gained through mutagenesis and protein depletion studies in particular for $\beta$-arrestins, which would indiscriminately affect recruitment of $\beta$-arrestin to receptors, desensitization, endocytosis and $\beta$-arrestin-mediated signalling ${ }^{21-23}$. Specific pharmacological probes targeting $\beta$-arrestin/AP2 complexes would be invaluable for determining the role of this complex and clathrin-mediated endocytosis in GPCR signalling.

In this light, we have used a virtual screening approach to identify specific inhibitors of $\beta$-arrestin/AP2 complexes. For this purpose, we took advantage of a well-defined groove within the $\beta 2$-adaptin ear platform subdomain, which accommodates the carboxyl-tail of $\beta$-arrestin ${ }^{20}$, hence providing a putative site for a small molecule interfering with the $\beta$-arrestin/AP2 interaction. On the basis of this structural insight, we combined virtual screening with a sensitive bioluminescence resonance energy transfer (BRET)-based assay ${ }^{24}$ to identify and validate novel inhibitors of the $\beta$-arrestin/ $\beta 2$-adaptin interaction. From five compounds found to modulate the $\beta$-arrestin/ $\beta 2$-adaptin interaction, two were inhibitors and one of them, which we named $\beta$-arrestin/ $\beta 2$-adaptin interaction inhibitor (Barbadin), was further characterized and used as a tool to study the interplay between receptor GPCR internalization and signalling.

\section{Results}

Screening for a $\beta$-arrestin/ $\boldsymbol{\beta} 2$-adaptin interaction inhibitor. To identify candidate inhibitors of the $\beta$-arrestin/ $\beta 2$-adaptin interaction, we first performed a structure-based virtual screen through the use of molecular docking calculations (Fig. 1a, and methods). We took advantage of the available coordinates of the crystal structure of a complex between the $\beta 2$-adaptin ear domain of the clathrin adaptor protein AP2 and a C-terminal peptide of $\beta$-arrestin1 (PDB entry 2IV8) (ref. 20). In this complex, the $\beta$-arrestin peptide is situated in a groove located in the $\beta 2$-adaptin ear platform subdomain, where Phe-388, Phe-391 and Arg-395 from $\beta$-arrestin1 interact with key Glu-849, Tyr-888 and Glu-902 residues of $\beta 2$-adaptin. The virtual screen was performed using a region of the $\beta 2$-adaptin ear platform that included the entire binding groove as the target, and the Myriascreen diversity collection of 10,000 compounds selected for their structural diversity and drug-likeness from an original chemical library of 300,000 molecules. Subsequently to docking calculations, the poses of the best-ranked molecules based on predicted binding energy (196 compounds) were visually inspected to select the candidates that make favourable interactions with residues from the $\beta 2$-adaptin groove, reported to be critical for $\beta$-arrestin binding ${ }^{19}$. Among these best candidates, 52 compounds were selected based on availability criteria. The list of these compounds with their acquisition number is presented in Supplementary Table 1.

To assess the ability of the 52 compounds to affect the $\beta$-arrestin/ $\beta 2$-adaptin interaction, we used a BRET-based assay that directly monitors the interaction between these two proteins following agonist-stimulation of GPCRs (ref. 24). The vasopressin type-2 receptor (V2R), that was previously shown to promote a large BRET increase between $\beta$-arrestin1-RlucII and $\beta 2$-adaptinYFP upon arginine vasopressin (AVP) stimulation ${ }^{24}$ (Fig. 1b), was chosen as receptor model for the screen. Before assessing the ability of the 52 compounds to modulate the BRET between $\beta 2$-adaptin-YFP and $\beta$-arrestin1-RlucII, we verified whether the molecules could spectrally interfere with BRET measurements. When tested in HEK293 cells overexpressing either the $\beta$-arrestin1-RlucII or the $\beta 2$-adaptin-YFP alone, 11 of the 52 compounds that had a significant effect on either luminescence or fluorescence signals were discarded (Supplementary Fig. 1). The remaining 41 compounds were tested in live cells, using the aforementioned BRET-based assay in which the V2R, $\beta 2$-adaptin-YFP and $\beta$-arrestin1-RlucII were co-expressed. As shown in Fig. 1c, five compounds significantly modulated the AVP-promoted BRET. Compounds \#14, \#19 and \#20 potentiated, whereas compounds \#33 and \#42 inhibited the AVP-promoted BRET between $\beta 2$-adaptin-YFP and $\beta$-arrestin1-RlucII. Compounds \#14, \#19 and \#20 might favour the interaction between $\beta$-arrestin 1 and $\beta 2$-adaptin, or modify the complex in a way that brings the YFP and RlucII moieties closer, or in an orientation which is more permissive for energy transfer. Although they may be interesting molecules in their own rights, we focused on characterizing compounds \#33 and \#42 because we sought to identify inhibitors of the $\beta 2$-adaptin/ $\beta$-arrestin complex.

To assess the potency of these compounds, concentrationresponse curves of the inhibitory actions of the compounds on 
the V2R-stimulated $\beta$-arrestin/ $\beta 2$-adaptin interaction were carried out. In addition to compounds \#33 and \#42, compound $\# 1$ was included in the analysis as a negative control (Fig. 2a-c). As expected, \#1 was completely inactive even at the highest concentration used (Fig. 2a), whereas both \#33 and \#42 showed concentration-dependent inhibitory responses. While \#33 had a low-potency $(>50 \mu \mathrm{M})$ that was difficult to estimate with precision due to incomplete inhibition curve (Fig. 2b), \#42 showed a well-defined sigmoidal inhibitory curve yielding an estimated $\mathrm{IC}_{50}$ of $19.1 \mu \mathrm{M}$ for $\beta$-arrestin1 (Fig. $2 \mathrm{c}$ ) and $15.6 \mu \mathrm{M}$ for $\beta$-arrestin2 (Supplementary Fig. 2a). Compound \#42, which structure is shown in Fig. 2d, represented a validated hit for a potential inhibitor of the complex and hence named Barbadin, and further characterized at the expense of \#33 that showed lower potency. First, the reversible mode of action of Barbadin was assessed by incubating cells with Barbadin for $30 \mathrm{~min}$ and monitoring BRET between $\beta 2$-adaptin and $\beta$-arrestin1 following, or not, extensive wash before AVP stimulation. As shown in Supplementary Fig. 2b, the washing procedure completely prevented the action of Barbadin demonstrating its reversibility.

To further investigate the potential binding mode of Barbadin on AP2, we examined the docking poses obtained for this compound. The docking calculations resulted in a single best pose, based on its prevalence among the possible solutions and the lowest binding energy that positioned Barbadin within the groove of the $\beta 2$-adaptin platform subdomain (Fig. 2e). The benzylphenyl moiety of Barbadin tightly fits a hydrophobic pocket lined mainly by Phe-837, Leu-838, Ile-876, Ala-877 and Tyr- 888 , via a set of non-polar and $\pi-\pi$ aromatic interactions. Superimposition of the docking pose of Barbadin with the $\beta 2$-adaptin/ $\beta$-arrestin $C$-tail co-crystal structure suggests that both phenyl rings of Barbadin are adopting very similar binding modes as both $\beta$-arrestin's key Phe-391 and Phe-395 residues (Fig. 2f). The thieno-pyrimidinone moiety interacts through $\pi-\pi$ aromatic interactions with Trp-841, and also through a network of two hydrogen bonds involving Tyr-888 and Glu-902 (Fig. 2e), two residues of $\beta 2$-adaptin shown to be critical for the binding of $\beta$-arrestin ${ }^{19}$. To investigate the role of the benzylphenyl moiety in Barbadin's inhibitory activity, we conducted a preliminary structure-activity relationship study with four analogues of Barbadin. As shown in Supplementary Fig. 3, a branched aliphatic and/or extended phenyl group on Barbadin's thienopyrimidinone core is essential for its inhibitory action, consistent with the docking pose.

In addition, to assess the direct binding of Barbadin to $\beta 2$-adaptin we performed a thermal-shift assay using purified appendage domain of $\beta 2$-adaptin ( $\beta 2$-appendage, amino-acids with sequence: 700-937). The stability curves obtained in Fig. $2 \mathrm{~g}$ show that, similarly to a 20 -mer $\beta$-arrestin C-tail peptide known to bind to the $\beta$-appendage ${ }^{20}$, Barbadin promoted a dosedependent rightward shift of the melting temperature consistent a

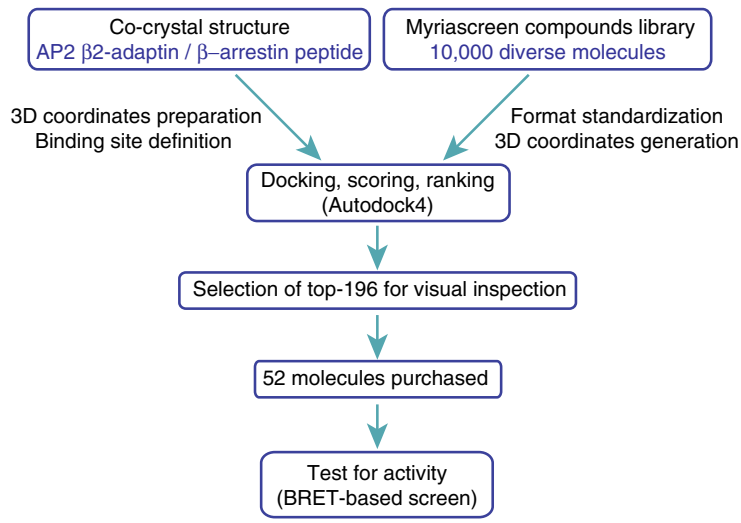

C

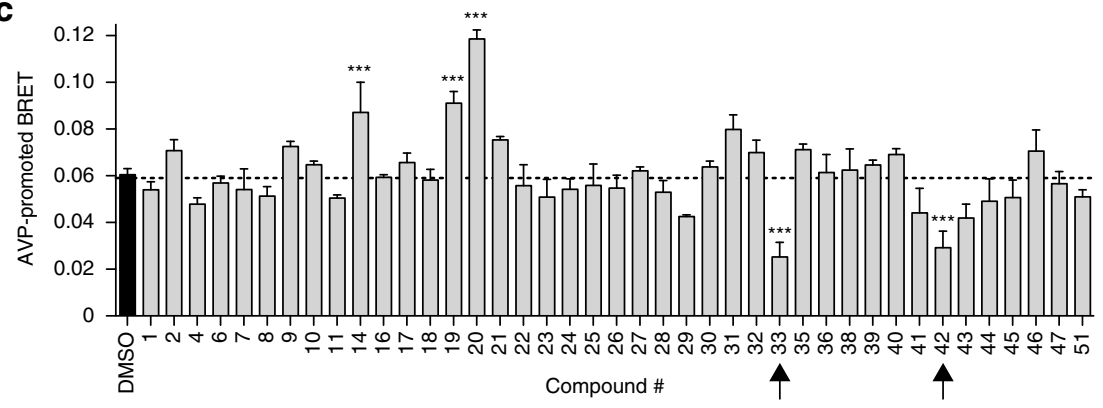

$\mathrm{V} 2 \mathrm{R}$

Interaction: AP2/ßarr1
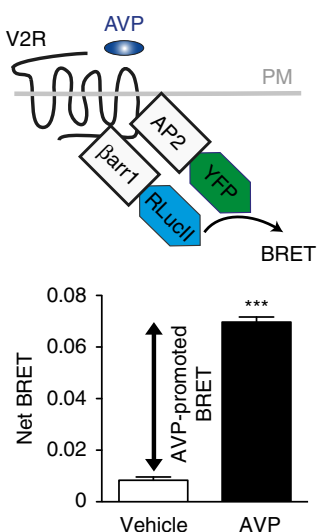


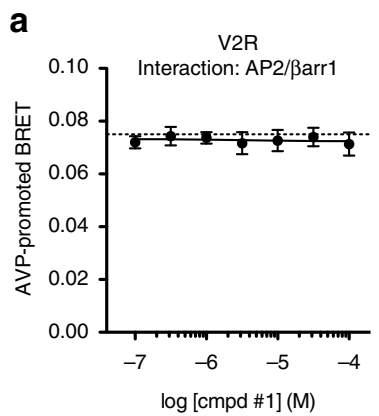

d

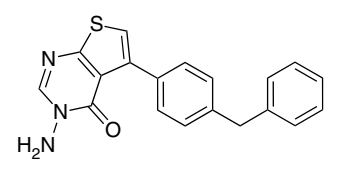

Barbadin (compound \#42)
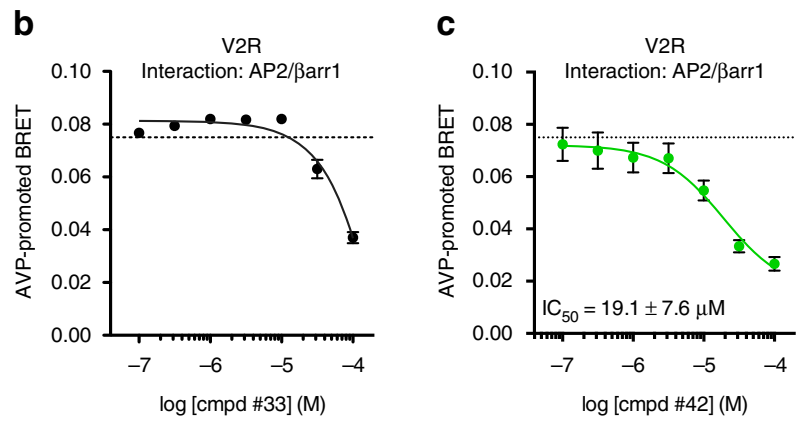

e

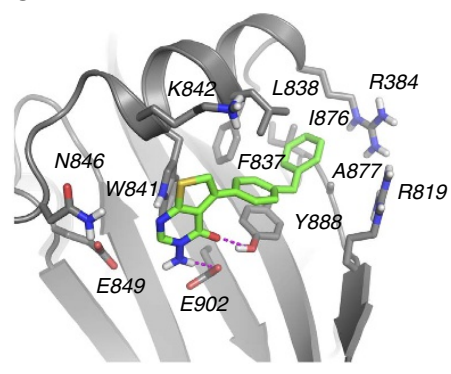

f

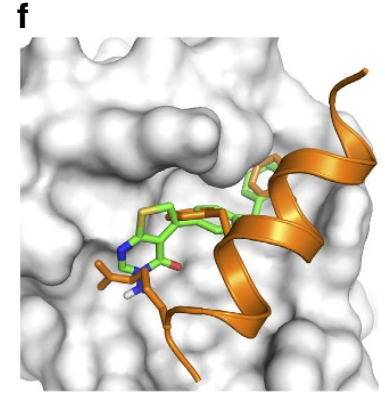

g
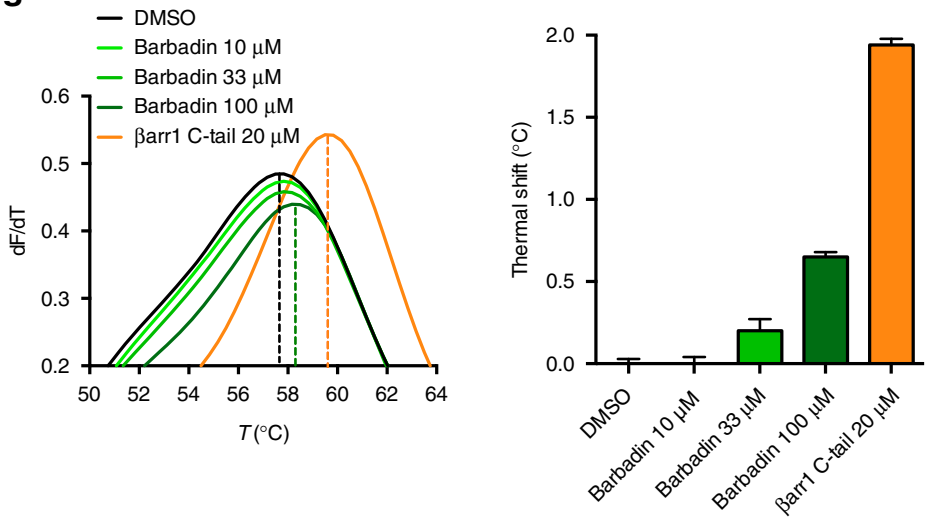

Figure 2 | Identification of Barbadin (compound \#42) as an inhibitor of the interaction between $\boldsymbol{\beta 2}$-adaptin and $\boldsymbol{\beta}$-arrestin. (a-c) Concentrationresponse curves of compounds \#1, \#33 and \#42 selected from the BRET-based screen (Fig. 1) using the same $\beta 2$-adaptin/ $\beta$-arrestin1 interaction assay. Dotted line represents the level of AVP-promoted BRET upon pre-incubation with DMSO. Data are the mean \pm s.e.m. of three independent experiments. (d) Chemical structure of Barbadin (IUPAC name: 3-amino-5-(4-benzylphenyl)-3H,4H-thieno[2,3-d]pyrimidin-4-one). (e,f) Docking pose of Barbadin (green sticks) within the groove of $\beta 2$-adaptin platform subdomain (grey ribbon (e), or surface (f)) that is the site of interaction with $\beta$-arrestin (orange ribbon and sticks (f)). $\beta 2$-adaptin residues known to interact with $\beta$-arrestin are labelled and shown as grey stick. Hydrogen-bonds interactions between Barbadin and both Tyr-888 and Glu-902 are depicted as magenta dotted lines (e). Superimposition of Barbadin with the $\beta$-arrestin1 C-terminus peptide as in the co-crystal structure (PDB entry 2IV8), where Phe-388, Phe-391 and Arg-395 are the three key residues for $\beta$-arrestin binding interaction (shown from top to bottom as orange sticks) (f). (g) Thermal denaturation of $\beta 2$-adaptin (residues 700-937) and concentration-dependent stabilization effect of Barbadin. The maximum of the first derivatives of fluorescence ( $\mathrm{dF} / \mathrm{dT}$ ) data from differential scanning fluorimetry corresponds to the melting temperatures ( $\mathrm{Tm}$, indicated with a dotted line) of $\beta 2$-adaptin in the presence of DMSO, Barbadin or $\beta$-arrestin1 C-tail peptide (positive control) at the indicated concentrations.

with a stabilization of the $\beta$-appendage due to the direct binding of the compound.

Barbadin selectively inhibits the $\beta$-arrestin/AP2 interaction. To rule out the possibility that Barbadin interferes directly at the level of the V2R, we assessed its effect on the $\beta$-arrestin1/ $\beta 2$-adaptin interaction by BRET, promoted by two additional GPCRs, the $\beta 2$-adrenergic receptor ( $\beta 2 \mathrm{AR}$ ) and the angiotensinII type-1 receptor (AT1R) (Fig. 3a-c). As was the case for the V2R, Barbadin inhibited the BRET between $\beta$-arrestin1-RlucII and $\beta 2$-adaptin-YFP promoted by the activation of both receptors. The $\beta 2 A R$ was selected because it differs from the V2R and AT1R in its mode of interaction with the $\beta$-arrestins ${ }^{7}$. The $\beta 2 \mathrm{AR}$ is classified as a class A receptor, interacting transiently with $\beta$-arrestins and rapidly recycling back from the endosomes to the cell surface, whereas V2R and AT1R are class B receptors forming tighter receptor $/ \beta$-arrestin complexes that reside for longer times in endosomes before being targeted to lysosomal degradation. These observations strongly suggest that the inhibition occurs at the level of the $\beta$-arrestin/ $\beta 2$-adaptin interaction and is not a receptor specific effect.

We next evaluated the mode of action of Barbadin by testing its effect on the other isoform of $\beta$-arrestin, $\beta$-arrestin2, that is 
a

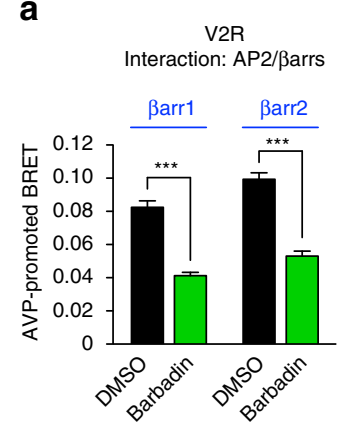

b
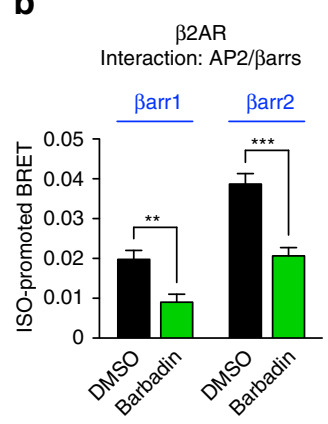

f

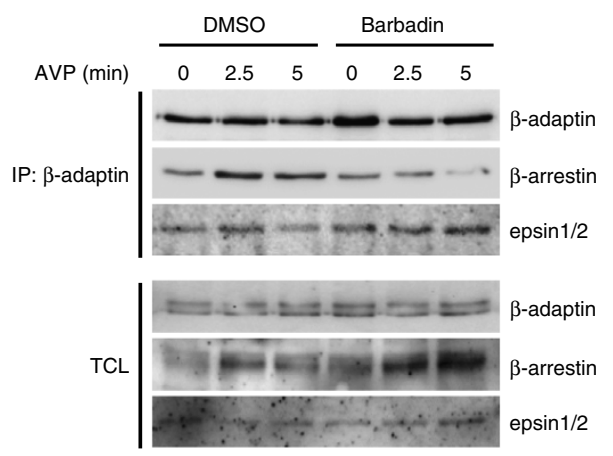

c

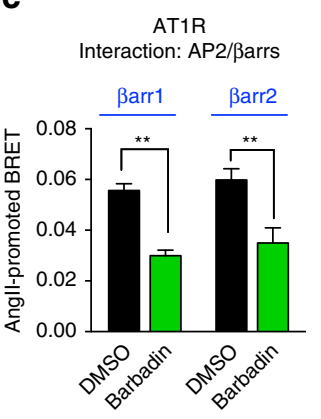

d

e
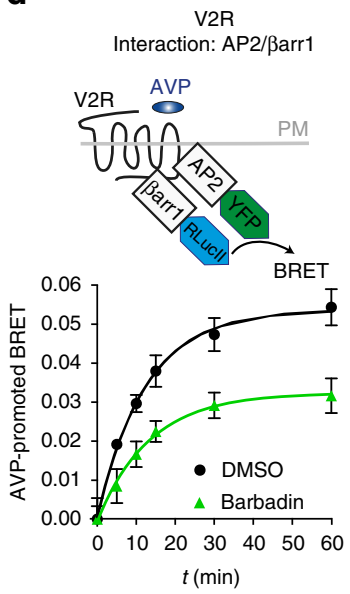

$\mathrm{V} 2 \mathrm{R}$

Interaction: V2R/ßarr1

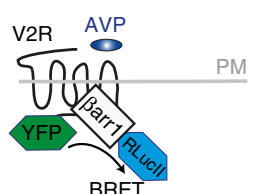

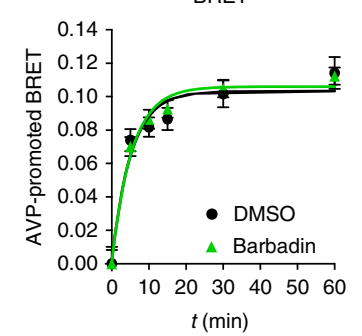

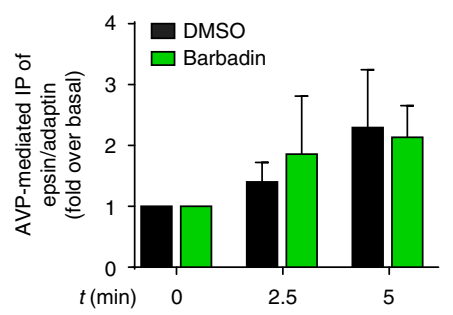

g
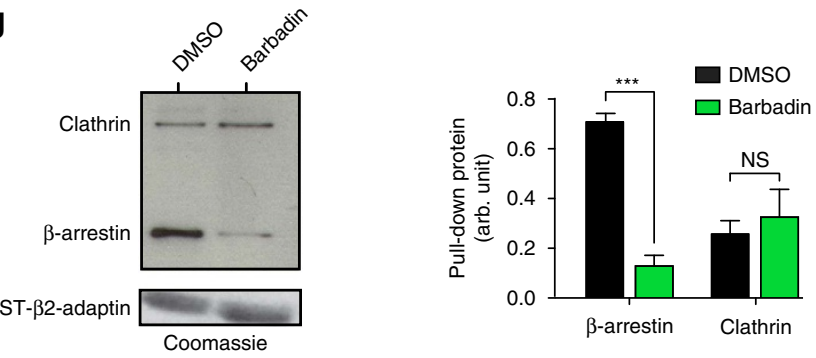

Figure 3 | Barbadin specifically blocks the interaction between $\boldsymbol{\beta 2}$-adaptin and $\boldsymbol{\beta}$-arrestin. (a-c) BRET-based assay monitoring the interaction between $\beta 2$-adaptin-YFP and either $\beta$-arrestin1-Rlucll or $\beta$-arrestin2-Rlucll. HEK293T cells were pre-incubated with DMSO or Barbadin (100 $\mu$ M) for 30 min before $45 \mathrm{~min}$ receptor stimulation with AVP $(100 \mathrm{nM}, \mathbf{a})$, ISO $(10 \mu \mathrm{M}, \mathbf{b})$ or Angll $(100 \mathrm{nM}, \mathbf{c})$. Data are the mean \pm s.e.m. of at least three independent experiments and unpaired $t$-test were used to assess statistical significance $\left({ }^{\star \star \star} P<0.001 ;{ }^{\star \star} P<0.005\right)$. (d,e) BRET-based kinetics monitoring the interaction between $\beta$-arrestin1-Rlucll and $\beta 2$-adaptin-YFP (d) or V2R-YFP (e) in HEK293T cells pretreated with DMSO or Barbadin (100 $\mu$ M) for 30 min before receptor stimulation with AVP $(100 \mathrm{nM})$ for the indicated times. Data are the mean \pm s.e.m. of three independent experiments. (f) Effect of Barbadin on the co-immunoprecipitation between $\beta$-arrestins and AP2. HEK293SL cells expressing V2R and Flag- $\beta$-arrestin2 were pretreated for 20 min with DMSO or Barbadin $(50 \mu \mathrm{M})$ before stimulation by AVP $(1 \mu \mathrm{M})$ for 2.5 or 5 min. Endogenous AP2 complexes (using the AP1/2 antibody) were immunoprecipitated (IP) from total cell lysates (TCL), and then analysed by western blot using anti-Flag, anti-epsin or anti-adaptin antibodies as described in the Material and Methods. TCLs represent $5 \%$ of input used for IP. IP were quantified over three independent experiments and statistical significance was assessed by a two-way ANOVA followed by Bonferroni's post-hoc tests $\left({ }^{\star} P<0.05\right)$. (g) Effects of Barbadin on the pull-down of $\beta$-arrestin1 and clathrin with GST- $\beta 2$-adaptin. DMSO or Barbadin $(100 \mu \mathrm{M})$ were incubated with GST- $\beta 2$-adaptin (592-937) beads. HEK293T cells transfected with Flag- $\beta$-arrestin1 were lysed and added to the beads. The amounts of GST- $\beta 2$-adaptin were detected by Coomassie, whereas $\beta$-arrestin1 and clathrin associated with GST- $\beta 2$-adaptin were detected by western blot using anti-Flag and anti-clathrin (heavy chain) antibodies, respectively. Relative intensities were normalized to the GST input for each condition and densitometry data are the mean \pm s.e.m. of three independent experiments and analysed using a two-way ANOVA followed by Bonferroni's post-hoc tests (NS, non-significant; ${ }^{\star \star \star} P<0.001$ ).

highly homologous to $\beta$-arrestin1 and would be predicted to interact with $\beta 2$-adaptin in a similar manner. As shown in Fig. 3a-c, Barbadin significantly inhibited the interaction between $\beta 2$-adaptin and both $\beta$-arrestins after stimulation of V2R, $\beta 2 A R$ or AT1R. Moreover, the extent of inhibition was comparable, in all cases Barbadin inhibiting the BRET signal by $\approx 50 \%$. The higher agonist-promoted signal observed for $\beta$-arrestin 2 versus $\beta$-arrestin1 upon $\beta 2 \mathrm{AR}$ stimulation, compared to the similar signals measured for both $\beta$-arrestin isoforms following V2R or AT1R stimulation, is consistent with the notion that class A, but not class $B$ receptors bind $\beta$-arrestin 2 with greater avidity than $\beta$-arrestin1 (refs 7,24).

To further assess whether Barbadin acts by selectively inhibiting the interaction between $\beta 2$-adaptin and $\beta$-arrestin, and not by inhibiting the recruitment of $\beta$-arrestin to GPCRs, the effect of Barbadin was also tested on the time-dependent 
AVP-promoted BRET between either $\beta 2$-adaptin-YFP and $\beta$-arrestin1-RlucII or V2R-YFP and $\beta$-arrestin1-RlucII (Fig. 3d,e). Barbadin strongly inhibited AVP-promoted BRET between $\beta$-arrestin1 and $\beta 2$-adaptin but was without effect on the $\mathrm{V} 2 \mathrm{R} / \beta$-arrestin1 BRET induced upon AVP stimulation, thus confirming a selective action on the $\beta$-arrestin/ $\beta 2$-adaptin complex. Similar results were obtained for the class A $\beta 2 \mathrm{AR}$ (Supplementary Fig. 4a,b).

Fluorescence confocal microscopy confirmed that Barbadin did not inhibit the recruitment of $\beta$-arrestin2 to the plasma membrane upon V2R activation (Supplementary Fig. 4c). In fact, co-localization of $\mathrm{V} 2 \mathrm{R}$ and $\beta$-arrestin 2 at the plasma membrane was more readily detected following Barbadin treatment as compared to control conditions, consistent with the notion that it does not affect receptor $/ \beta$-arrestin interaction but that it inhibits internalization of receptor/ $\beta$-arrestin complexes, hence increasing their accumulation at the plasma membrane.

The specificity of the effect of Barbadin on the endocytic complex formation was also validated by co-immunoprecipitation and GST pull-down experiments. Figure $3 \mathrm{f}$ illustrates that Barbadin significantly inhibited AVP-promoted co-immunoprecipitation between endogenous $\beta$-adaptins and $\beta$-arrestin $1 / 2$ but did not affect the association with epsin, a protein interacting with lower affinity than $\beta$-arrestin at a different site on $\beta 2$-adaptin's ear platform subdomain ${ }^{25}$. Similarly, Barbadin significantly inhibited the ability of GST- $\beta 2$ adaptin to pull-down $\beta$-arrestin1 (Fig. $3 \mathrm{~g}$ ) but had no effect on the pull-down of clathrin, which is known to interact at $\beta 2$-adaptin sites (the hinge region and the ear $\beta$-sandwich subdomain) that are distinct from the interaction site of $\beta$ arrestin. Taken together, these results indicate that Barbadin selectively blocks the interaction between $\beta$-arrestin and $\beta 2$-adaptin as predicted by the in silico docking and the BRETbased assays.

Barbadin blocks $\beta$-arrestin/AP2-dependent GPCR endocytosis. Because the interaction between $\beta$-arrestins and $\beta 2$-adaptin is important for initiating receptor internalization, we next sought to determine whether Barbadin could be used as a pharmacological tool, to block the ligand-promoted endocytosis of GPCRs. For this purpose, we used enhanced bystander BRET (ebBRET) trafficking sensors allowing to monitor both receptor disappearance from the plasma membrane (rGFP-CAAX sensor, Fig. 4a) and their accumulation in early endosomes (rGFP-FYVE, Fig. 4e) in spectrometric and microscopy-based assays ${ }^{26}$. As shown in Fig. 4a-h, Barbadin blocked the time-dependent agonist-induced loss of $\mathrm{V} 2 \mathrm{R}, \beta 2 \mathrm{AR}$ and AT1R from the cell surface (Fig. 4b-d), and consequently prevented their appearance into early endosomes (Fig. $4 \mathrm{f}-\mathrm{h}$ ), demonstrating that it acts as an efficient endocytosis inhibitor. Notably, the $\mathrm{IC}_{50}$ for the inhibitory action of Barbadin on endocytosis are similar to those observed for its action on the $\beta$-arrestin/AP2 interaction (Fig. $2 c$ and Supplementary Fig. 2a), consistent with its mode of action (Supplementary Fig. 5a-h). The effect of Barbadin on endocytosis was further confirmed using BRET-microscopy allowing to image receptor localization at the plasma membrane (Fig. 4i and Supplementary Fig. 5i), and in early endosomes (Supplementary Fig. 5j), coherent with the spectrometric measurements (Fig. 4b-d,f-h).

To orthogonally validate the BRET-based endocytosis measurements, we used flow-cytometry (FACS) with double-tagged receptors where a HA epitope and a Venus fluorescent protein are fused to amino- and carboxy-termini, respectively, allowing to monitor both cell surface (HA immunofluorescence) and total receptor (venus fluorescence) expression ${ }^{27}$. As shown in Fig. 5a- c, agonist stimulation of cells expressing either the V2R or $\beta 2 A R$ led to a time-dependent disappearance of cell surface signals corresponding to agonist-promoted endocytosis. Barbadin significantly inhibited FACS-monitored endocytosis to extents comparable to Pitstop2 and Dyngo-4a, two known inhibitors of both clathrin-dependent and independent endocytosis ${ }^{28-30}$ (Fig. $5 \mathrm{a}-\mathrm{c}$ ). Since both $\beta 2 \mathrm{AR}$ and V2R are known to undergo $\beta$-arrestin and $\beta 2$-adaptin-dependent endocytosis, the effect of Barbadin on agonist-promoted endocytosis is likely explained by the inhibitory action of Barbadin on the $\beta$-arrestin/ $\beta 2$-adaptin interaction. To further validate this mode of action, we used the type $A$ endothelin receptor $\left(\mathrm{ET}_{\mathrm{A}} \mathrm{R}\right)$ that undergoes $\beta$-arrestin-dependent but clathrin-independent endocytosis into caveolae $e^{31}$, and which involves the recruitment of $\beta$-arrestin to the receptor without engagement of AP2 (ref. 24). As predicted from its proposed mode of action, Barbadin did not inhibit endothelin-promoted $\mathrm{ET}_{\mathrm{A}} \mathrm{R}$ endocytosis (Fig. 5d). In contrast, Pitstop2 significantly blocked agonist-stimulated $\mathrm{ET}_{\mathrm{A}} \mathrm{R}$ endocytosis consistent with its clathrin-independent action ${ }^{29}$. To further assess Barbadin selectivity, we tested its effect on transferrin endocytosis occurring through clathrin-coated pits and involving the transferrin receptor (TfR), a non-GPCR that interacts directly with AP2 independently of $\beta$-arrestin ${ }^{32}$. Barbadin did not significantly inhibit the internalization of transferrin at any of the time points examined, whereas it was blocked by Pitstop2 as early as 2 min after stimulation (Fig. 5e,f). The ability of Barbadin to block the endocytosis of natively expressed GPCR was also confirmed by monitoring the agonistpromoted loss of AT1R from cell surface using radio-ligand binding in vascular smooth muscle cells (Supplementary Fig. 6). Taken together, these results indicate that Barbadin is a suitable tool to study $\beta$-arrestin/AP2-dependent endocytosis.

To gain insight on the inhibitory properties of Barbadin on clathrin-mediated internalization of GPCRs, we next examined the sub-cellular distribution of $\beta$-arrestin, AP2 and clathrin by confocal fluorescence microscopy in V2R-expressing cells (lacking endogenous $\beta 2$-adaptin to facilitate the incorporation of CCPs-labelled $\beta 2$-adaptin into AP2 complexes, Supplementary Fig. 7a) transfected with $\beta$-arrestin2-mCherry, $\beta 2$-adaptin-CFP and clathrin-light-chain-YFP. As shown in Fig. 6a, under basal conditions $\beta 2$-adaptin and clathrin colocalized in CCPs, whereas $\beta$-arrestin is diffuse in the cytosol. On AVP stimulation, $\beta$-arrestin translocates to CCPs where it colocalizes with $\beta 2$-adaptin and clathrin (Fig. 6a,b). A pre-treatment of $30 \mathrm{~min}$ with Barbadin did not disrupt the CCPs nor prevented the translocation of $\beta$-arrestin to pits (Fig. 6b). In fact, Barbadin led to an increase in $\beta$-arrestin/ $\beta 2$-adaptin colocalization (Supplementary Fig. $7 \mathrm{~b}, \mathrm{c}$ ) that was even more evident upon longer agonist stimulation (Fig. 6c). The maintenance of the CCPs integrity upon Barbadin treatment is consistent with our previous biochemical data showing that Barbadin has no significant effect on the binding of clathrin to $\beta 2$-adaptin (Fig. 3g). The observation that $\beta$-arrestin translocation to the plasma membrane is not inhibited by Barbadin is also in agreement with our BRET data demonstrating that Barbadin does not interfere with the recruitment of $\beta$-arrestin to V2R (Fig. 3e) or $\beta 2 \mathrm{AR}$ (Supplementary Fig. 4b). Although, the lack of obvious inhibition of $\beta$-arrestin and $\beta 2$-adaptin colocalization by Barbadin appears counter-intuitive considering it blocks the interaction between these two proteins, the localization of $\beta$ arrestin to the pits does not result exclusively from its interaction with $\beta 2$-adaptin. Indeed, many other protein-protein interactions have been implicated in stabilizing GPCR/ $\beta$-arrestin complexes at the PM and into CCPs, including direct binding of $\beta$-arrestin's $\mathrm{N}$-terminal domain ${ }^{33}$ to the $\mu$-subunit of AP2 and an indirect clathrin-mediated link between AP2 and $\beta$-arrestin's C-terminal 
a

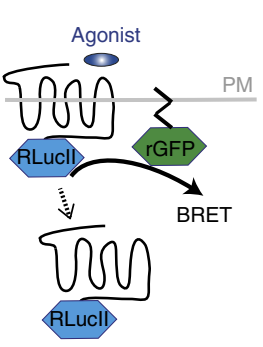

e

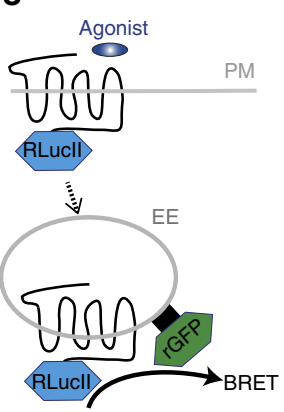

b

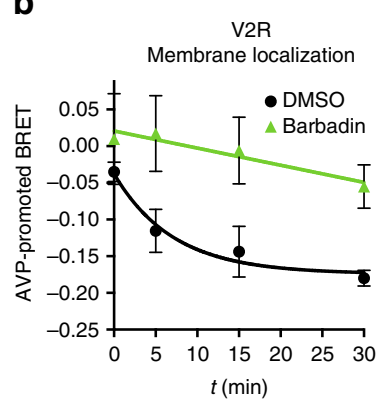

f

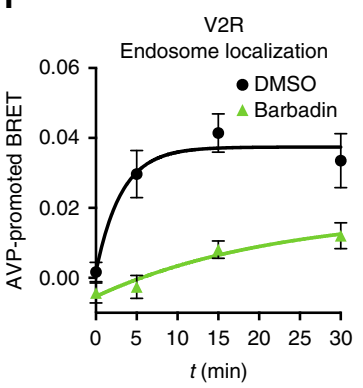

C

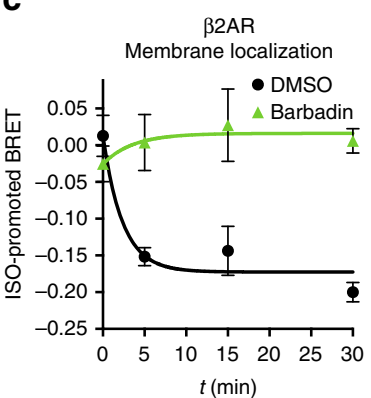

g

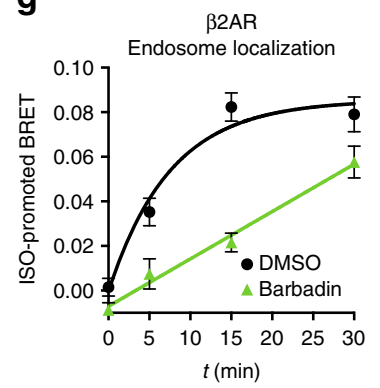

d

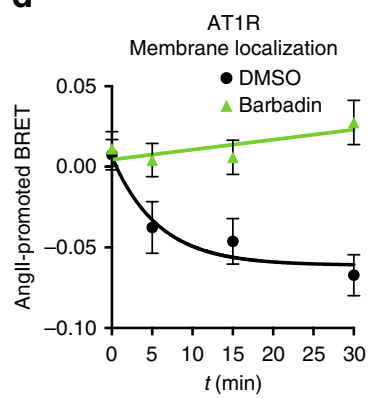

h

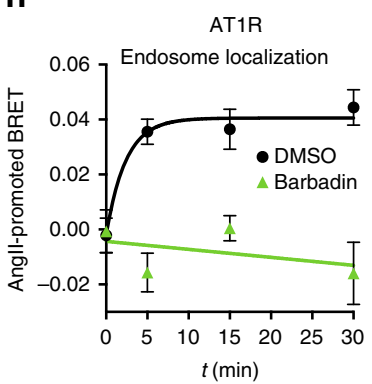

i
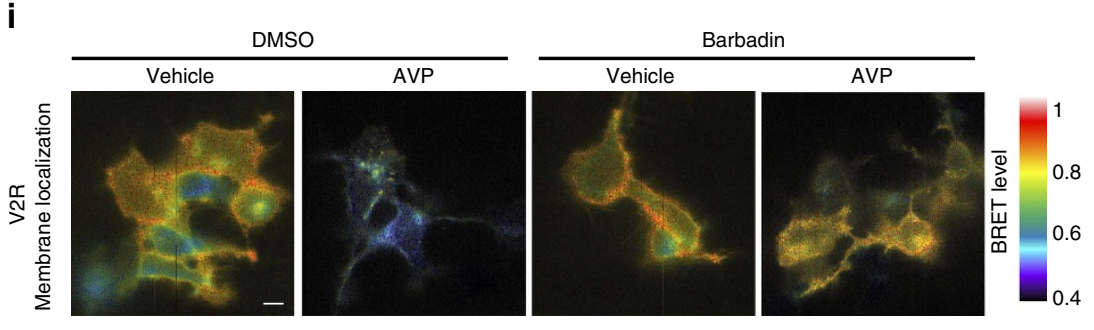

Figure 4 | Barbadin inhibits GPCRs endocytosis. (a,e) Schematic representation of the ebBRET-based assay used to follow agonist-induced receptor loss from the cell surface by monitoring the interaction between receptor-RLucll and rGFP-CAAX (a) or its translocation into endosomes using rGFP-FYVE (e). (b-d,f-h) V2R, $\beta 2 A R$ or AT1R interaction with either rGFP-CAAX (b-d, respectively) or rGFP-FYVE (f-h, respectively) was assessed by BRET following HEK293T cells pre-incubation with DMSO or Barbadin $(100 \mu \mathrm{M})$ for 30 min before AVP $(100 \mathrm{nM})$, ISO $(10 \mu \mathrm{M})$ or Angll $(1 \mu \mathrm{M})$ stimulation for the indicated times. Data are the mean \pm s.e.m. of a least three independent experiments. (i) V2R localization was imaged by BRET. HEK293T cells were transfected with V2R-Rlucll and rGFP-CAAX, pretreated with DMSO or Barbadin (100 $\mu$ M) for 30 min and then stimulated with $100 \mathrm{nM}$ AVP for 30 min. To generate BRET images, the ratio of acceptor photon counts to donor photon counts was calculated for each pixel and expressed as a colour-coded heat map (lowest being black and purple, and highest red and white). Scale bar, $10 \mu \mathrm{m}$.

domain $^{34,35}$. Therefore, the persistence of $\beta$-arrestin in CCPs and its colocalization with AP2 in the presence of Barbadin most likely reflects $\beta$-arrestin's ability to directly interact with other components of the CCPs, in particular clathrin itself bringing it in close proximity to $\beta 2$-adaptin, resulting in colocalization, without a direct interaction. To further test this possibility, we took advantage of a mutant form of $\beta$-arrestin lacking the major site of interaction with clathrin ( $\beta$-arrestin2- $\Delta$ Clath). As shown in Supplementary Fig. $7 d$, although $\beta$-arrestin $2-\Delta$ Clath was still recruited into CCPs, where it largely colocalized with $\beta 2$-adaptin upon AVP stimulation, Barbadin treatment resulted in a marked reduction of $\beta$-arrestin2- $\Delta$ Clath clustering in these CCPs as can be seen by its more diffuse distribution at, or near, the PM, and the reduced colocalization of the mutant $\beta$-arrestin with $\beta 2$-adaptin. These findings are consistent with the notion that even though the interaction between $\beta$-arrestin and AP2 plays a critical role for clustering receptor/ $\beta$-arrestin complexes in CCPs, other interactions such as the ones with clathrin are also important, and that inhibiting only one of them is insufficient to prevent its targeting to CCPs. Yet, Barbadin clearly inhibited the traffic of $\beta$-arrestin from the plasma membrane to endosomes that is seen upon sustained agonist stimulation of receptor (Fig. 6c). This suggests that destabilizing the interaction between the $\beta 2$-adaptin and $\beta$-arrestin with Barbadin delays CCPs-mediated internalization kinesis.

Barbadin modulates GPCR signalling. Several studies have suggested a role for $\beta$-arrestin and/or endocytosis in downstream signalling. Since Barbadin blocks $\beta$-arrestin/ $\beta 2$-adaptin interaction and the subsequent endocytosis without affecting the recruitment of $\beta$-arrestin to the receptor (Fig. 3d), it represents a unique tool to selectively assess the role of $\beta$-arrestin/ $\beta 2$-adaptindependent endocytosis in signalling. Given that $\beta$-arrestinmediated endocytosis has been proposed to contribute to the activation of the MAPK by many GPCRs ${ }^{36,37}$ including the V2R for which the ERK1/2 activation in HEK293 cells is entirely $\beta$ arr-dependent ${ }^{38}$, we assessed the effect of Barbadin on the V2R-stimulated ERK1/2 activity. As shown in Fig. 7a,c, Barbadin completely blocked the AVP-stimulated ERK1/2 activation. This effect was selective since Barbadin did not block EGF-stimulated ERK1/2 (Fig. 7b,c). These data indicate that the engagement of $\beta 2$-adaptin by $\beta$-arrestin is essential for the $\beta$-arrestin-dependent 
a

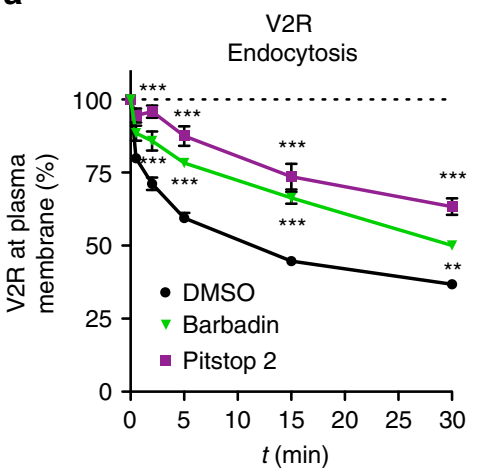

d

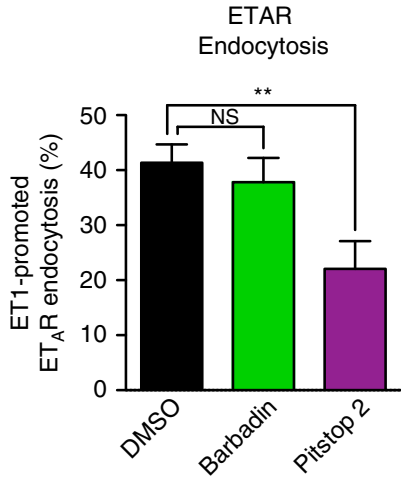

b
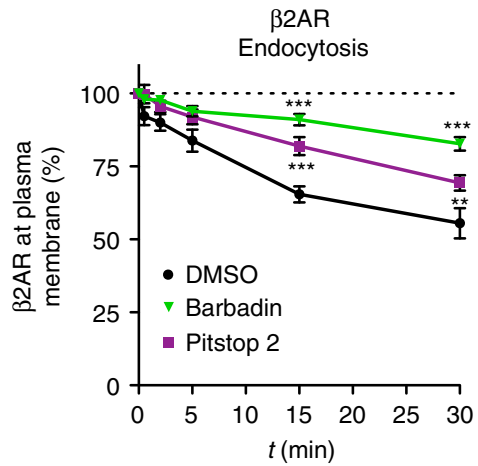

e

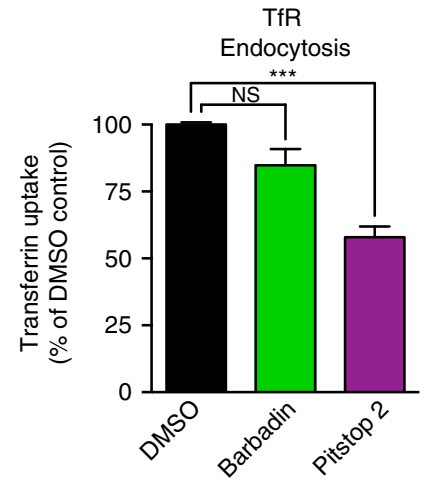

C

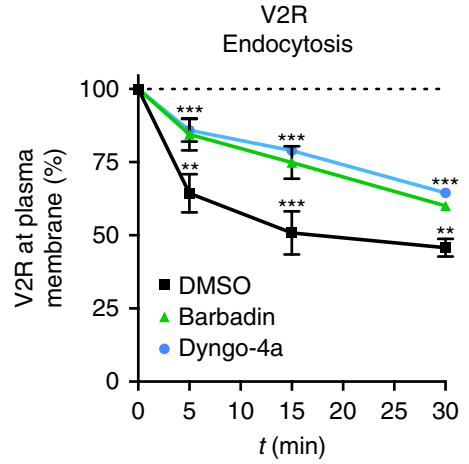

f

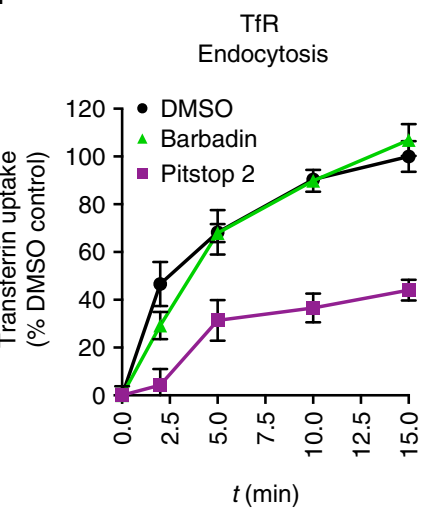

Figure 5 | Barbadin inhibits the $\boldsymbol{\beta}$-arrestin- and AP2-dependent endocytosis of GPCRs. (a-c) Cell surface expression of HA-V2R-Venus (a,c) or HA- $\beta 2 A R-V e n u s ~(b)$ transfected in HEK293T cells was monitored by FACS following pre-incubation with DMSO, Barbadin (100 $\mu$ M), Pitstop2 (100 $\mu$ M) or Dyngo-4a $(30 \mu \mathrm{M})$ for $30 \mathrm{~min}$, before agonist stimulation (AVP $(100 \mathrm{nM}, \mathbf{a}, \mathbf{c})$, ISO $(10 \mu \mathrm{M}, \mathbf{b})$ ) at the indicated times. Data are the mean \pm s.e.m. of at least three independent experiments. Statistical significance of the effect of Barbadin, Pitstop 2 and Dyngo, as compared to DMSO, was assessed by a two-way ANOVA followed by Bonferroni's post-hoc tests ( ${ }^{\star \star} P<0.01$; ${ }^{\star \star \star} P<0.001$ ). (d) Cell surface expression of HA-ET $\mathrm{A}_{\mathrm{A}}$ was monitored by FACS following pre-incubation with DMSO, Barbadin $(100 \mu \mathrm{M})$ or Pitstop2 $(100 \mu \mathrm{M})$ for $30 \mathrm{~min}$, before ET1 $(10 \mathrm{nM})$ stimulation for 30 min. Data are the mean \pm s.e.m. of at least three independent experiments. Statistical significance was assessed by a one-way ANOVA followed by Tuckey's post-hoc tests (NS, non-significant; $\left.{ }^{\star \star} P<0.01\right)$. (e,f) Native transferrin receptor $(T f R)$ uptake was monitored by FACS in HeLa cells. Cells were pretreated with DMSO, Barbadin $(100 \mu \mathrm{M})$, or Pitstop2 $(100 \mu \mathrm{M})$ for $30 \mathrm{~min}$, then incubated with Alexa Fluor 633-conjugated transferrin antibody $\left(100 \mu \mathrm{gl} \mathrm{ml}^{-1}\right)$ for $30 \mathrm{~min}$ at $4{ }^{\circ} \mathrm{C}$, and finally shifted to $37^{\circ} \mathrm{C}$ for $15 \mathrm{~min}(\mathbf{e})$ or the indicated time (f). Data are the mean \pm s.e.m. of three independent experiments. Statistical significance was assessed by a one-way ANOVA followed by Tuckey's post-hoc tests (NS, non-significant; ${ }^{\star \star} P<0.01 ;{ }^{\star \star \star} P<0.001$ ).

activation of ERK1/2 by V2R and are consistent with a role for endocytosis in this signalling cascade. When considering the $\mathrm{G}$ protein-dependent signalling cascades such as the activation of adenylyl cyclase, the $\beta$-arrestin-promoted endocytosis has been proposed to contribute both to the desensitization-resensitization cycle $^{2,39}$, as well as sustained endosomal Gs signalling ${ }^{1-13}$. As shown in Fig. 7d,e, Barbadin significantly blunted the timedependent increase in cyclic AMP (cAMP) production promoted by the agonist stimulation of either V2R or $\beta 2 A R$. This effect was concentration-dependent yielding an $\mathrm{IC}_{50}$ of $\sim 7.9 \mu \mathrm{M}$ (Fig. $7 \mathrm{~g}, \mathrm{~h}$ ), which is consistent with the potency of Barbadin to inhibit the $\beta$-arrestin/ $\beta 2$-adaptin interaction (Fig. $2 \mathrm{c}$ ). The selectivity of action is confirmed by the lack of effect of Barbadin on the forskolin-stimulated cAMP production (Fig. 7i) or the activation of Gs as measured by BRET (ref. 40) (Fig. 7f). Such inhibition of the $\beta 2$ AR-stimulated cAMP production could result from the lack of recycling of resensitized receptor to the plasma membrane that normally follows endocytosis. However, the latter explanation is unlikely because, in contrast to $\beta 2 \mathrm{AR}, \mathrm{V} 2 \mathrm{R}$ does not recycle back to the plasma membrane following endocytosis, and therefore this process would not contribute to the inhibition of V2R-stimulated cAMP production observed here. These results therefore indicate, as was recently suggested for some receptors, that inhibition of endocytosis may prevent the adenylyl cyclase signalling that persists following endocytosis ${ }^{11,12}$.

\section{Discussion}

The present study led to the identification of the first chemical probe that specifically inhibits the interaction between $\beta$-arrestin and the $\beta 2$-adaptin subunit of AP2. We validated the important role of this interaction for receptor endocytosis by demonstrating that Barbadin blunts clathrin-mediated endocytosis of three prototypical GPCRs ( $\beta 2 \mathrm{AR}, \mathrm{V} 2 \mathrm{R}$ and AT1R) without interfering with the translocation of $\beta$-arrestin to the receptor, nor with the interaction of AP2 with other components of the endocytic machinery. When used to dissect the role of the $\beta$-arrestin/AP2 interaction in GPCR signalling, Barbadin was found to inhibit the activation of ERK and CAMP production elicited by receptor stimulation, demonstrating that the $\beta$-arrestin/AP2 complex plays a role not only in receptor trafficking but also in signalling.

This work also illustrates that virtual screening can successfully identify small molecule inhibitors of protein-protein interactions. Despite the fact that identifying protein-protein interface inhibitors remains challenging due to the large surfaces of these interfaces and their planar architecture, a number of successes 
a
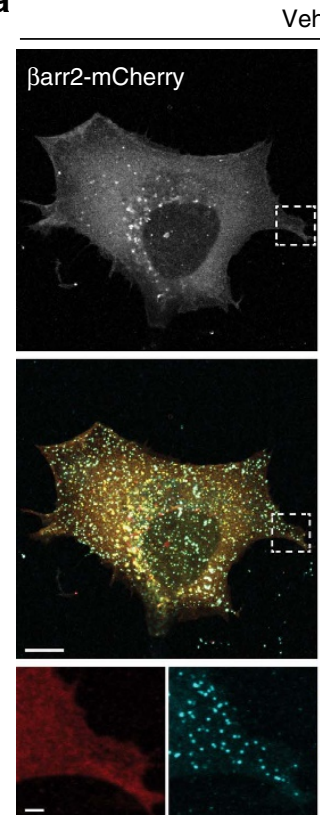

Barr2-mCherry $\beta 2 A d-C F P$
Vehicle
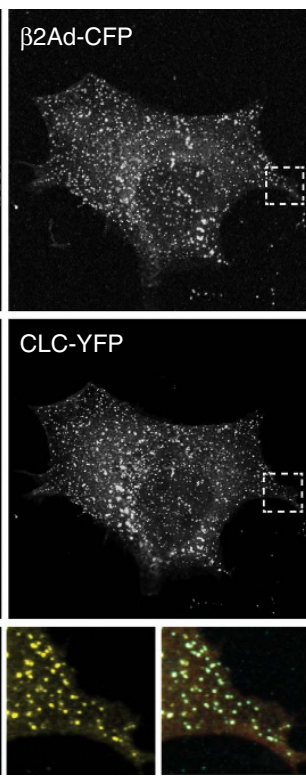

CLC-YFP

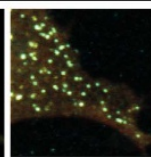

Overlay
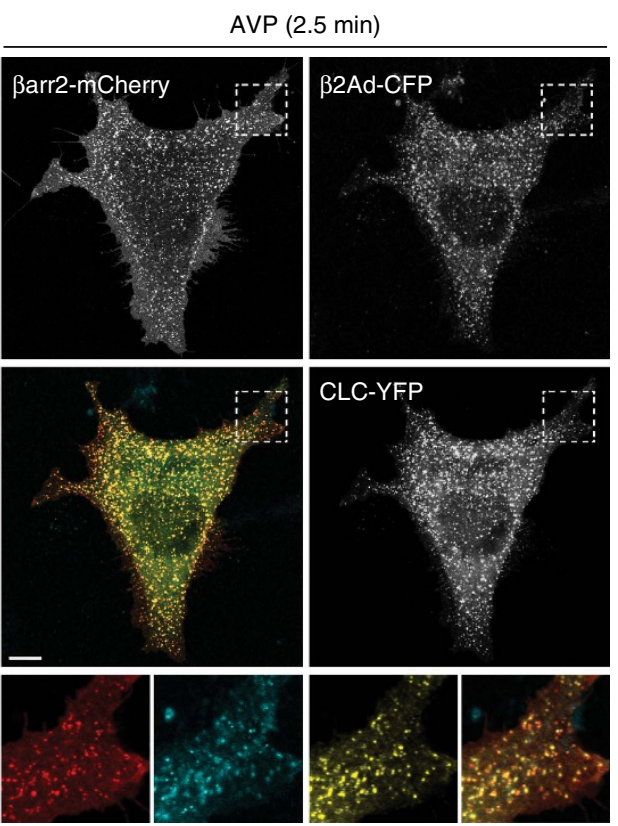

Barr2-mCherry $\quad \beta 2 A d-C F P$

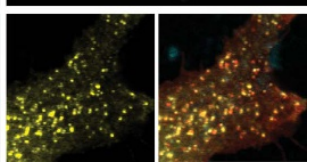

CLC-YFP

Overlay

b
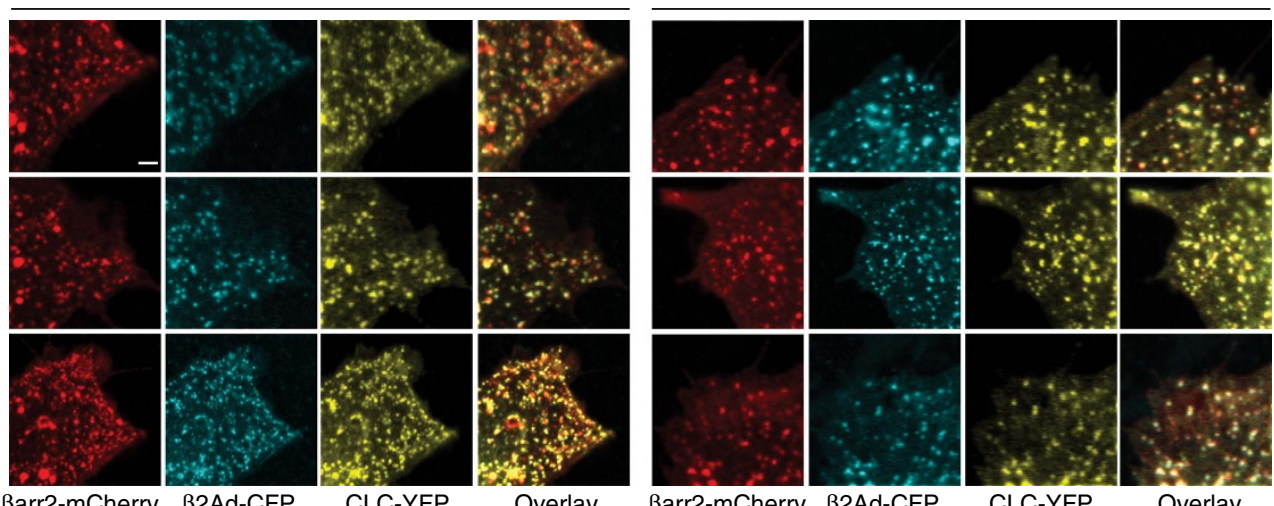

ßarr2-mCherry $\beta 2 A d-C F P$

CLC-YFP

Overlay

$C_{\text {AVP }}$

$2.5 \min$
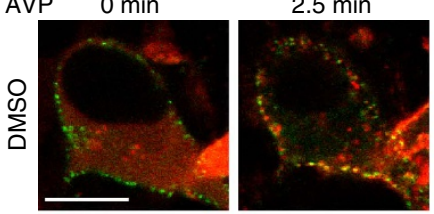

$5.5 \mathrm{~min}$
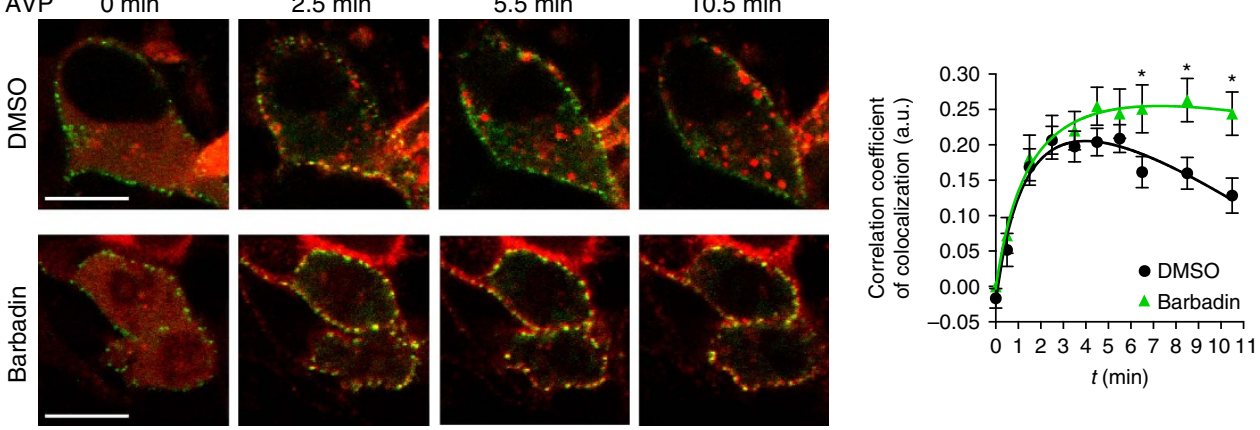

Barr2-mCherry /B2Ad-YFP

Figure 6 | Barbadin induces the retention of receptor/ $\beta$-arrestin complexes in clathrin-coated pits (CCPs) at the membrane. (a,b) Confocal images and colocalization of $\beta$-arrestin2, $\beta 2$-adaptin, and clathrin light chain-(CLC) in CCPs from AVP-stimulated cells expressing V2R. $\beta 2$-adaptin depleted HEK293 cells (CRISPR- $\beta 2$ Ad-LY5) were transfected with $\beta$-arrestin2-mCherry, $\beta 2$-adaptin-CFP and CLC-YFP, and HA-V2R, and serum-starved for 30 min in the absence or presence of Barbadin $(10 \mu \mathrm{M})$, before being either left non-stimulated (vehicle) or stimulated with AVP $(1 \mu \mathrm{M})$ for 2.5 min. Cells were then fixed as described in the Methods section before visualization. Shown in the top panels are black and white micrographs of acquired fluorescent signals from the three-tagged proteins in each channel (red, cyan and yellow), and in colour, are the overlay images. Lower colour insets are close-up images from boxed areas. (b) Colour images represent individual and overlay fluorescent signals taken from different areas, from cells transfected, treated and stimulated as in a. Scale bars in images of whole cells, $10 \mu \mathrm{m}$; and insets, $2 \mu \mathrm{m}$. Colocalization quantification is presented in Supplementary Fig. 7b-c. (c) Colocalization and quantification of $\beta$-arrestin2-mCherry and $\beta 2$-adaptin-YFP in live HEK293T cells stably expressing V2R. Cells were pretreated with DMSO or Barbadin $(10 \mu \mathrm{M})$ for $30 \mathrm{~min}$ before stimulation with AVP $(1 \mu \mathrm{M})$ for the indicated durations. Co-localization was quantified using the Pearson correlation coefficient over three independent experiments using 33 or 24 cells for DMSO and Barbadin condition, respectively. Statistical significance of the effect of Barbadin as compared to DMSO was assessed by a two-way ANOVA followed by Bonferroni's post-hoc tests $\left({ }^{\star} P<0.05\right)$. 
a

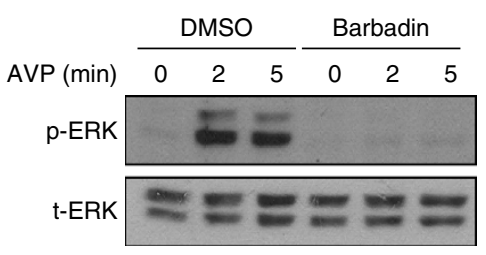

d

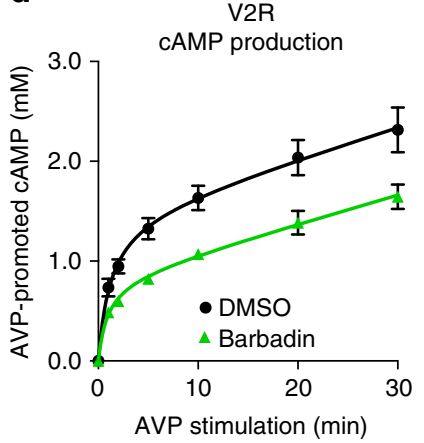

g

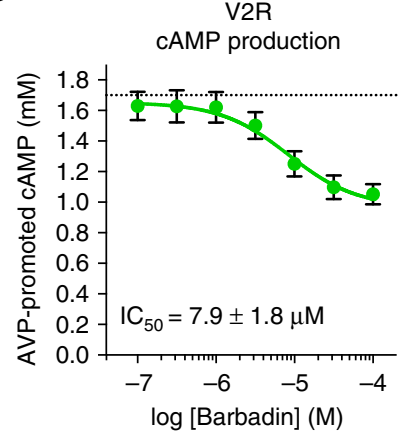

b

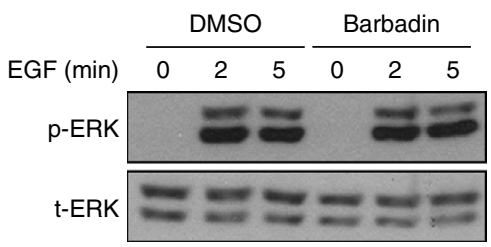

e

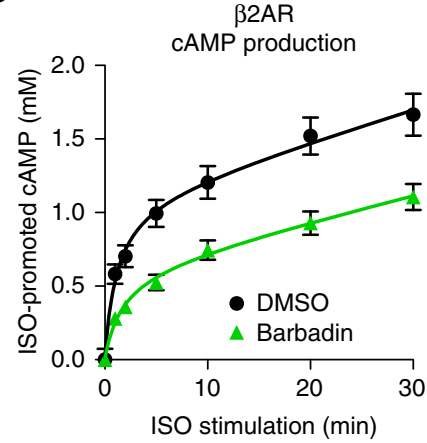

h

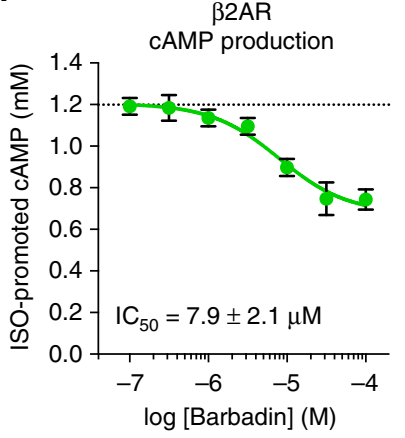

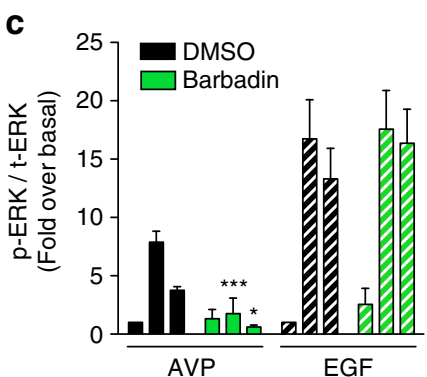

f

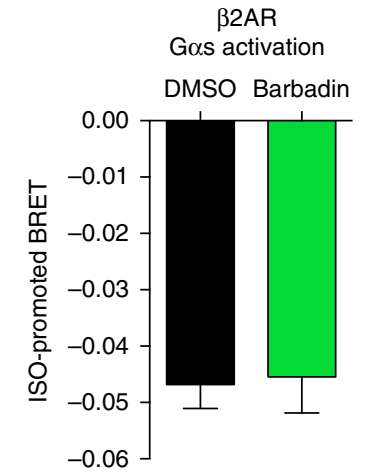

i

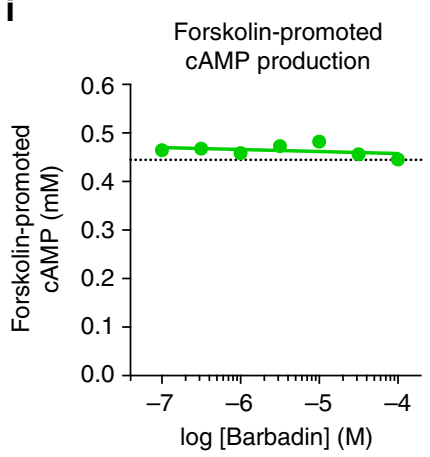

Figure 7 | Barbadin inhibits ERK1/2 activation and cAMP accumulation following agonist-stimulation of GPCR. (a-c) Kinetics of ERK1/2 phosphorylation in HEK293T cells expressing V2R (a) or EGFR (b) and pretreated with DMSO or Barbadin (50 $\mu$ M) for 30 min before stimulation with AVP $(100 \mathrm{nM}, \mathbf{a})$ or EGF $\left(100 \mathrm{ng} \mathrm{ml}^{-1}, \mathbf{b}\right)$ at the indicated times. Western blots were quantified $(\mathbf{c})$ and data shown are the mean \pm s.e.m. of four independent experiments and analysed using a two-way ANOVA followed by Bonferroni's post-tests $\left({ }^{\star} P<0.05 ;{ }^{* \star \star} P<0.001\right)$. (d,e) Kinetics of the agonist-promoted accumulation of cAMP in HEK293T cells stably expressing V2R (d) or $\beta 2 A R$ (e) and pretreated with DMSO or Barbadin (50 $\mu$ M) for 30 min before stimulation with AVP $(100 \mathrm{nM}, \mathbf{d})$ or ISO $(10 \mu \mathrm{M}, \mathbf{e})$ at the indicated times. Data are the mean \pm s.e.m. of three independent experiments. (f) ISO-promoted Gs activation measured by BRET in HEK293T cells transfected with HA- $\beta 2 A R$, G $\alpha$ s-RLucll, G $\beta 1$ and G $\gamma 2-$ GFP10, pretreated with DMSO or Barbadin $(100 \mu \mathrm{M})$ for $30 \mathrm{~min}$, before ISO $(10 \mu \mathrm{M})$ stimulation for $5 \mathrm{~min}$. (g,h) Concentration-response curves of Barbadin effect on the intracellular cAMP production, in HEK293T cells stably expressing the V2R $(\mathbf{g})$ or the $\beta 2 A R(\mathbf{h})$, upon agonist stimulation for $15 \mathrm{~min}$ with AVP (100 nM) or ISO (1 $\mu$ M), respectively, following pre-treatment with DMSO (grey dotted line) or Barbadin (green) at the indicated concentrations for 30 min. Data are the mean \pm s.e.m. of three independent experiments. (i) Concentration-response curves of Barbadin effect on the intracellular cAMP production, in HEK293T cells stimulated with forskolin $(10 \mu \mathrm{M})$ for $15 \mathrm{~min}$. Same DMSO and Barbadin pre-treatments as in $(\mathbf{g}, \mathbf{h})$. Data are the mean \pm s.e.m. of three independent experiments.

have now been reported for protein complexes bearing favourable quaternary architectures ${ }^{41,42}$. In this context, the fact that the groove delineating the $\beta$-arrestin binding site on the $\beta 2$-adaptin ear platform subdomain is well-defined ${ }^{19,20}$ undoubtedly contributed to conduct reliable docking calculations that led to the identification of a validated inhibitor.

The docking pose and thermal-shift assay experiments suggest that Barbadin binds directly to the platform domain of $\beta 2$-adaptin and relies on residues that are also involved in the interaction with $\beta$-arrestins. Indeed, the role of the benzyl-phenyl moiety of Barbadin in mimicking Phe388 and Phe391 of $\beta$-arrestin for binding $\beta 2$-adaptin, is supported by the observations that analogues lacking one of the two phenyl rings (analogues A, B and compound 43) or altering the distance and flexibility between these rings (analogue C) showed lower inhibitory action on the $\beta$-arrestin/ $\beta 2$-adaptin interaction. Consistent with such a mode of binding that competes for the binding of $\beta$-arrestin $C$-tail to the platform domain of $\beta 2$-adaptin, Barbadin inhibited the interaction between $\beta 2$-adaptin and $\beta$-arrestin in a reversible manner without affecting the recruitment of $\beta$-arrestin to the receptor. Such selectivity may not be surprising given that the targeted domain of interaction between AP2 and $\beta$-arrestin is remote from the polar core of $\beta$-arrestin that interacts with the receptors ${ }^{16,43}$. Furthermore, as the 
engagement of AP2 by $\beta$-arrestin follows the recruitment of $\beta$-arrestin to the receptors ${ }^{24}$, blocking AP2 binding would not be predicted to influence the initial $\beta$-arrestin binding to the receptor. The topologically driven selectivity of Barbadin is also illustrated by its lack of effect on the interaction between $\beta 2$-adaptin and other components of the CCPs such as clathrin and epsin, which bind distinct sites on $\beta 2$-adaptin compared with $\beta$-arrestin. Consistent with the selectivity of Barbadin, the formation of CCPs is not disturbed as demonstrated by co-localization of AP2 and clathrin.

As predicted by its inhibitory action on the $\beta$-arrestin/ $\beta 2$-adaptin interaction, Barbadin significantly inhibited receptor endocytosis as quantified by flow-cytometry and BRET, and imaged by fluorescence microscopy experiments monitoring V2R and $\beta$-arrestin cell surface localization. Although Barbadin did not affect the recruitment of $\beta$-arrestin to the plasma membrane upon V2R stimulation, it prevented its subsequent trafficking to endosomes. This inhibition resulted in a large fraction of the $\beta$-arrestin accumulating at the cell surface and co-localizing with AP2 and clathrin in CCPs. This finding suggests that the $\beta$-arrestin-dependent accumulation of V2R-cargo into forming CCPs is a multi-step process involving numerous interactions with structural and endocytic accessory proteins of the coat (Fig. 8). Interestingly, it also suggests that $\beta$-arrestin's interaction with $\beta 2$-adaptin is essential in the maturation of clathrin-coated vesicle-mediated internalization (for example, accumulation of the $\mathrm{V} 2 \mathrm{R} / \beta$-arrestin complex into clathrin-coated vesicles at plasma membrane and their final invagination). In that respect, the effect of Barbadin is reminiscent of the expression of an AP2 complex lacking the appendage domain of $\alpha$-adaptin-which like the $\beta$-appendage that binds $\beta$-arrestin for initiating GPCR endocytosis, also recruits other regulatory/accessory proteins on its platform domain for the internalization of other classes of receptors-where it prevented the maturing and invagination of $\mathrm{CCPs}^{13,44}$. The fact that Barbadin did not prevent the clustering of receptor/ $\beta$-arrestin complexes in CCPs is not unexpected (Fig. $6 \mathrm{a}-\mathrm{c}$ ), considering that $\beta$-arrestin also forms low affinity interactions with clathrin through its carboxy tail ${ }^{45}$, and with AP2 via its $\mu 2$ subunit through $\beta$-arrestin's $\mathrm{N}$-terminal domain ${ }^{46}$. Indeed, when preventing the former interaction, the inhibitory effect of Barbadin for clustering receptor/ $\beta$-arrestin complexes in CCPs was more readily observed. The robust Barbadin-promoted inhibition of both agonist-promoted BRET between $\beta 2$-adaptinYFP and $\beta$-arrestin-RlucII, as well as endocytosis for the $\beta 2 \mathrm{AR}$, V2R and AT1R support previous observations demonstrating that the interaction between the carboxyl tail of $\beta$-arrestin and the $\beta 2$-adaptin subunit of AP2 is preponderant in the initial steps of agonist-promoted internalization of many GPCRs ${ }^{17}$. The selective action of Barbadin on endocytosis processes mediated by the $\beta$-arrestin/AP2 complex was supported by its lack of effect on the ligand-independent and ligand-promoted internalization of transferrin and endothelin-1 receptors, respectively, which are $\beta$-arrestin- and AP2-independent ${ }^{24,31,32}$. The demonstration that Barbadin blocks receptor endocytosis, not only in engineered cells heterologously expressing GPCRs but also in vascular smooth cells endogenously expressing AT1R, paves the way for its use to assess the role of the $\beta$-arrestin/ $\beta 2$-adaptin complexes in native systems.

The observed effects of Barbadin on the ERK1/2 and cAMP signalling activities of the receptors confirm the role played by endocytosis in the control of specific GPCR signalling modalities $9,11,12$ and more particularly unambiguously demonstrate the essential, but perhaps underappreciated, role of the $\beta$-arrestin/ AP2 interaction in this process. Barbadin completely blocks the V2R-stimulated ERK1/2 activation confirming the role of $\beta$-arrestin in this signalling pathway for V2R (ref. 38), but the result also points to a central role of endocytosis- and CCPs-mediated activation of MAPK by the receptor/ $\beta$-arrestin complex. This finding is consistent with the emerging role of $\beta$-arrestin in CCPs for MAPK signalling, which was described for the Bradykinin B2 receptor and recently shown for the $\beta 1$-adrenergic receptor ${ }^{47,48}$. Thus, inhibition of $\beta$-arrestin signalling in both CCPs and endosomes (because Barbadin prevented the trafficking of receptor/ $\beta$-arrestin complexes to these intracellular compartments) most likely contributes to the total blockade of V2R-mediated activation of ERK1/2 by Barbadin. This inhibitory action of Barbadin on ERK1/2

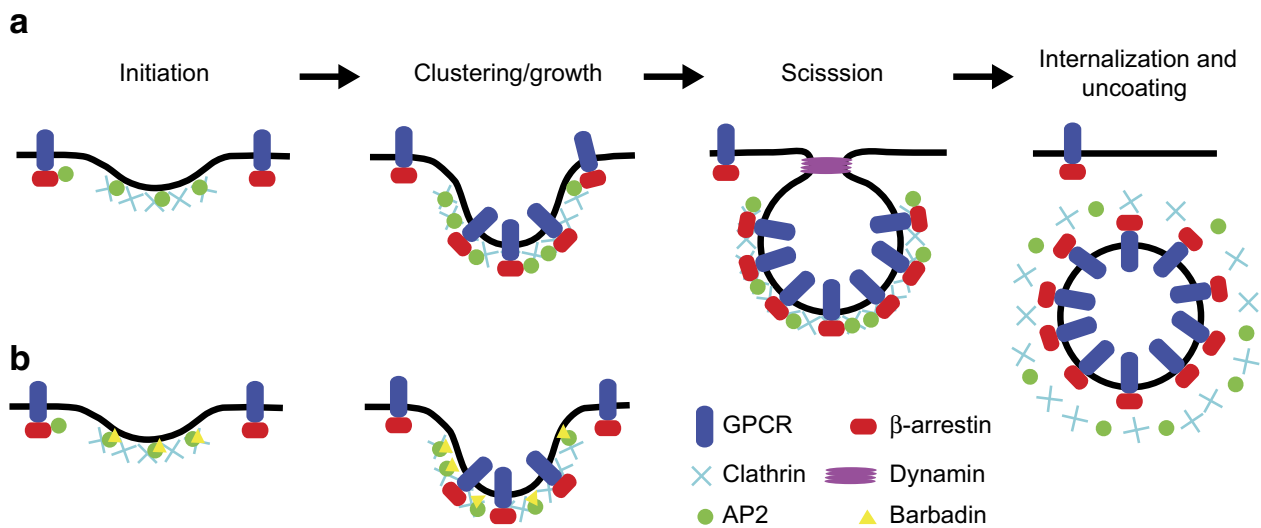

Figure 8 | Model for the biogenesis of clathrin-coated pits (CCPs) and Barbadin's effect on GPCRs endocytosis. (a) Initiation of CCPS formation involves the association of AP2 with phosphatidylinositol 4,5-bisphosphate (Ptdlns (4,5)P2) at the plasma membrane (PM) and the recruitment of clathrin to AP2 at sites of nucleation. Growth and stabilization of coated-vesicles requires the recruitment of additional AP2 and clathrin, and endocytic accessory proteins like epsin (not shown here) and $\beta$-arrestins. Agonist-activated GPCR/ $\beta$-arrestin complexes accumulate in CCPs through $\beta$-arrestin's interactions with AP2 ( $\beta 2$ and $\mu$ subunits) and clathrin, stabilizing further the growing coated-vesicles. Stabilization of GPCR/ $\beta$-arrestin complexes and the recruitment of endocytic effectors like dynamin allows the matured coated-vesicles to commit for invagination and scission from the PM, which is followed by the uncoating (that is, release of AP2 and clathrin) of internalizing vesicles. (b) In the presence of Barbadin, initiation of CCPs still occurs because clathrin and AP2 are effectively recruited at sites of nucleation. Some receptor/ $\beta$-arrestin complexes will still coalesce into nucleating CCPs through $\beta$-arrestin's binding with clathrin and its low affinity interaction to AP2 (for example, via the $\mu$ subunit). Because Barbadin prevents the interactions of $\beta$-arrestin with the appendage domain on the $\beta 2$-subunit of $\mathrm{AP} 2$, which prevents the stable formation of sufficient GPCR/ $\beta$-arrestin complexes in CCPs, the maturation of the coated-vesicles is hampered, and receptor internalization impeded. 
activation cannot be attributed to a non-specific off-target effect of the compound, on other components of the MAPK pathway since it did not affect ERK1/2 activation promoted by the EGF receptor. These results are therefore consistent with the notion that spatiotemporal GPCR-stimulated ERK1/2 activation occurs following clustering of receptor/ $\beta$-arrestin in CCPs and endocytosis of the complex in endosomes ${ }^{9,49}$.

The effect of Barbadin on the cAMP production stimulated by both $\beta 2 \mathrm{AR}$ and $\mathrm{V} 2 \mathrm{R}$ also provides new insights on the spatiotemporal regulation of signalling as it brings strong support to the emerging notion that GPCR-stimulated cAMP production continues after endocytosis of Gs-coupled receptors ${ }^{13,50-56}$, contrasting with the classical view that receptor endocytosis contributes only to the termination of cAMP signalling. Sustained interaction between receptor and $\beta$-arrestin at the plasma membrane upon inhibition of endocytosis could also directly contribute to the reduced cAMP accumulation by preventing reactivation of the receptor at the plasma membrane. The effect was specific to receptor-mediated cAMP production and did not result from an off-target effect on Gs or the adenylyl cyclase since Barbadin had no effect on the Gs activity as directly monitored by BRET or cAMP generation resulting from a direct activation of adenylyl cyclase by forskolin. The extension of endocytosisdependent cAMP production to the V2R is particularly interesting given the fact that this receptor does not recycle to the plasma membrane following endocytosis but is instead retained for an extended period of time in endosomal compartments before being targeted for degradation ${ }^{57}$. This result excludes the possibility that the diminution of V2Rpromoted cAMP production following Barbadin treatment could result from the accumulation of desensitized receptor at the plasma membrane that cannot be replaced by re-sensitized ones upon inhibition of endocytosis.

Barbadin is distinct from the existing endocytosis blockers as it selectively interferes with the $\beta 2$-adaptin/ $\beta$-arrestin interaction and thus solely blocks endocytic processes that are dependent on the interaction between $\beta$-arrestin and the appendage domain of the $\beta$-subunit of AP2. Existing pharmacological inhibitors such as dynasore $^{58}$, dynoles ${ }^{59}$ or dyngos ${ }^{30}$ inhibit all dynamin-dependent endocytic pathways, while pitstop1/2 (ref. 28) inhibit both clathrin-dependent and -independent endocytosis ${ }^{29}$. Although we cannot rule out the possibility that Barbadin interacts with other targets in cells, we found that it did not directly act on other components of the clathrin endocytic machinery, nor on important signalling effectors (for example, $\beta$-arrestin- and $G$ protein-dependent signalling promoted by GPCRs, cAMP production by adenyl cyclase and MAPK activation promoted by other receptors like EGFR) supporting a selective mode of action. Barbadin's selectivity of action on $\beta$-arrestin/AP2 interaction allows the dissection of the relative contribution of this complex to the regulation of GPCRs endocytosis and signalling, independently of other processes controlling cell surface density, and thus represents a valuable addition to the existing pharmacological toolbox ${ }^{60}$.

\footnotetext{
Methods

Materials. DMEM, FBS, penicillin, streptomycin, PBS and G418 were from Wisent Inc. Cell culture plates and dishes were purchased from BD Biosciences. Arginine vasopressin (AVP), isoproterenol (ISO), Angiotensin-II (AngII), Epidermal Growth Factor (EGF), endothelin 1 (ET1), sigmacote, poly-L-ornithine hydrobromide, 3-isobutyl-1-methylxanthine (IBMX), Triton X-100, mouse monoclonal anti- $\beta_{1}$ - and $\beta_{2}$-adaptins (AP1/2, clone 100/1, \#A4450), rabbit Anti-Flag antibody (\#F7425), anti-Flag (M2, \#F3165) and anti-mouse or anti-rabbit HRP conjugated antibodies (\#A9044 and \#A9169, respectively) were from Sigma-Aldrich. Poly-d-lysine was obtained from MatTek Corporation. Linear polyethylenimine $25-\mathrm{kDa}$ (PEI) was from Polysciences. BARR3978 antibody against $\beta$-arrestin was previously described ${ }^{61}$. Phospho-p42/p44 (pERK1/2, \#9106) and p42/p44 (ERK1/2, \#9102) antibodies were from Cell Signaling Technology.
}

Antibodies against clathrin heavy chain (Clone 23, 610499) and adaptin $\beta$ (Clone 74 , \#610381) were obtained from BD Biosciences. Epsin1/2 rabbit antibody was kindly provided by Peter McPherson (McGill University). Dithiobis succinimidyl propionate (DSP) was from Pierce. Coelenterazine H, coelenterazine $400 \mathrm{~A}$ and Prolume Purple were from Nanolight Technology. Mouse monoclonal anti-HA antibody (HA.11) was purchased from Covance (\#MMS-101 P). Anti-mouse Alexa Fluor 647 secondary antibody (A-21463), fluorescent transferrin conjugate (Alexa Fluor 633, T23362), puromycin and salmon sperm DNA were bought from Invitrogen. Pitstop2 was from Abcam (ab120687) and Dyngo (S7163) from SelleckChem. cAMP dynamic-2 kit was from Cisbio. Costar v-bottom polypropylene 96-wells plates were from Corning. White Optiplate 96-wells microplates and 384-well Proxiplates were purchased from PerkinElmer. Lumitrac 200 384-wells plates were from Greiner Bio-one. X-treme GENE HP reagent was from Roche and Strep-Tactin Sepharose beads from IBA Gmbh. $\beta$-arrestin 1 C-terminal peptide (sequence: DDDIVFEDFARQRLKGMKDD) was synthesized by Genscript, while CPM dye was purchased from ThermoFisher Scientific. Protein concentration were determined using a detergent compatible protein assay kit from Bio-Rad.

Differential scanning fluorimetry was done in a RotorGeneQ from Qiagen. Luminescence and BRET reading were performed in the Mithras LB 940 multidetector plate reader from Berthold Technologies. Cell surface expression of receptors was analysed in a LSR II flow cytometer from BD Biosciences. Radioactivity was counted using a PerkinElmer Wizard 1470 automatic $\gamma$-counter. For microscopy, colocalization analyses were performed using Zen software from Zeiss. Time-resolved fluorescence resonance energy transfer was read in an Artemis plate reader from Cosmo Bio USA.

Virtual screening. Virtual screening by docking has been performed on a computer cluster of 10 Intel Core 2 Quad $2.6 \mathrm{GHz}$ processors. The SD file of the Myriascreen compounds collection (library number T990000) has been requested to Sigma-Aldrich (www.sigmaaldrich.com). Canonicalization and three-dimensional coordinates generation of the compounds were performed using Chemaxon Standardizer, JChem 5.1.2 (www.chemaxon.com). Starting from the $\beta 2$-adaptin/ $\beta$-arrestin co-crystal structure (PDB entry 2IV8), the AutoDockTools ${ }^{62}$ interface was used to prepare the binding site of $\beta 2$-adaptin which was defined as a 30 - $\AA$ cubic box centred on the $\beta$-arrestin helical peptide bound to the $\beta 2$-adaptin ear platform subdomain. Docking was carried out using Autodock 4.0 (ref. 62) with 30 independent runs of simulation per compound docked. Autodock scoring function was used to rank compounds by lowest energy. For visual inspection of the best energy candidates, we chose to select any compounds within a range of $2.1 \mathrm{kcal} \mathrm{mol}^{-1}$ (s.e. of Autodock) from the best compound. The best 196 selected compounds, and the docked Barbadin analogues were visually analysed using PyMOL (PyMOL Molecular Graphics System, Version 1.4 Schrödinger, LLC) and the MOE package (Molecular Operating Environment (MOE), 2012.10, Chemical Computing Group Inc., 1010 Sherbooke St. West, Suite \#910, Montreal, QC, Canada, H3A 2R7, 2012).

Compounds acquisition and technical consideration. The 52 small organic compounds from the original screen were purchased from Sigma. Because Barbadin was later discontinued by Sigma, it was then acquired from Otava (\#0129700278). Barbadin analogues were acquired from Enamine (see Supplementary Table 1 for catalogue numbers). All compounds were solubilized in $100 \%$ DMSO at a $10 \mathrm{mM}$ stock concentration. To circumvent the possibility that Barbadin adheres to plastic, all assays were carried out using tips, tubes and 96-wells plates coated with Sigmacote, then rinsed extensively with water.

Plasmids and constructs. Plasmids encoding myc-V2R (ref. 63), V2R-YFP (ref. 63), HA-ETAR (ref. 64), HA-AT1R (ref. 65), $\beta$-arrestin1-RlucII (ref. 65), $\beta$-arrestin2-RlucII (ref. 66), $\beta$-arrestin2-YFP (ref. 67), $\beta$-arrestin2-mCherry (ref. 65), $\beta 2$-adaptin-YFP (ref. 68), GST- $\beta 2$-adaptin(592-937) (ref. 19), flag- $\beta$-arrestin1 (ref. 6), $\beta 2$ AR-RLucII (ref. 26), V2R-RLucII (ref. 26), AT1R-RLucII (ref. 26), rGFP-CAAX (ref. 26) and rGFP-FYVE (ref. 26) were previously described. $\beta 2$-adaptin-mCherry was generated by replacing the YFP moiety of $\beta 2$-adaptin-YFP with that of the mCherry using the AgeI and BsrGI sites. $\beta 2$-adaptin-CFP was generated by replacing the YFP moiety of $\beta 2$-adaptin-YFP with that of the CFP from the pECFP vector. Clathrin light chain-YFP was purchased from addgene (Cambridge, MA). The LIEF/AAEA substitution in human $\beta$-arrestin2-YFP ( $\beta$-arr2- $\Delta$ Clath-YFP) was generated by complementation PCR reaction, using the forward primer 5- GGACACCAACGCAGCTGAAGCC GATACCAACTATGCC-3 with the reverse 5- TGGCGACCGGTGGATCCCG GCAGAGTTGATCATCATAGTCG-3 primer containing the BamHI site, and the reversed primer 5- TCGGCTTCAGCTGCGTTGGTGTCCACAGGGACATC-3 and forward primer 5-AGATCTCGAGCTCAAGCTTATGGGGGAGAAAC-3 containing the HindIII site. The PCR product from the amplified complementing fragments was cloned into BamHI/HindIII sites by Gibson assembly (NEB). The $\beta 2 \mathrm{AR}$ construct was generated by inserting a polymerase chain reaction (PCR)amplified fragment encoding human $\beta 2 \mathrm{AR}$ into a pcDNA3.1 vector, between HindIII/XbaI. The $\beta 2$-adaptin(700-937)-StrepTagII construct was generated by inserting a PCR-amplified fragment encoding human $\beta 2$-adaptin (residues from 
700 to 937) into a pRSETA vector (Invitrogen), between the BamHI and Acc65I restriction sites. To generate HA- $\beta 2 \mathrm{AR}-\mathrm{V}$ enus encoding plasmid, the Venus sequence was first PCR-amplified and introduced into the previously described pIRESP-HA vector ${ }^{69}$. Then, the $\beta 2 A R$ sequence was PCR-amplified and inserted into pIRESP-HA-Venus vector by recombination using In-Fusion PCR Cloning Kit

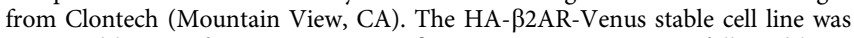
generated by transfecting pIRESP-HA- $\beta 2 \mathrm{AR}-\mathrm{Venus}$ in HEK293T followed by polyclonal selection of expressing cells using $3 \mu \mathrm{g} \mathrm{ml}^{-1}$ of puromycin. The expression vectors pIREShygro3 and pIRESpuro3 were from Clontech (Mountain View, CA). The plasmid encoding HA-V2R-Venus was made in two cloning steps. First, HA-V2R gene was PCR-amplified from pcDNA3.1 + + 3HA-V2R plasmid from Missouri S\&T cDNA resource centre (Rolla, MO), keeping one HA tag and removing the stop codon. The PCR product was then inserted in pIRESpuro3a vector. Then, the Venus sequence was PCR-amplified and inserted in pIRESpuro3a-HA-V2R. The resulting HA-V2R-Venus fusion sequence was then inserted into pIREShygro3 vector, yielding pIREShygro3-HA-V2R-Venus plasmid. The HA-V2R-Venus stable cell line was generated by transfecting pIREShygro3HA-V2R-Venus in HEK293T followed by polyclonal selection of expressing cells using $100 \mu \mathrm{g} \mathrm{ml}^{-1}$ of hygromycin B. All constructs were verified by DNA sequencing.

$\beta 2$-adaptin deletion in HEK293 cells (CRISPR- $\beta 2 A d)$ were generated using the CRISPR/Cas9 system PspCas9(BB)-2A-Puro (Px459v2) vector (Gift from Feng Zhang: Addgene plasmid $\# 62988)^{70}$ and the gRNA target sequences $\left(5^{\prime}\right.$-GTA TTTCACAACCAATAAAAA- $3^{\prime}$ and $5^{\prime}$-GGTCTGGCTACCTGCAGTAA- $3^{\prime}$ ) against the human AP2B1 gene (GenScript gRNA database). Each gRNA was cloned into the Px459v2 vector, and both constructs were transfected in HEK293 cells using Lipofectamine 2000 according to the manufacturer's instructions. The next day, medium supplemented with puromycin $\left(2 \mu \mathrm{g} \mathrm{ml}^{-1}\right)$ was added to cells for $48 \mathrm{~h}$ and cells were serially diluted and plated in 96-wells plates for generating individual colonies. Colonies were then verified for $\beta 2$-adaptin expression by western blot and by PCR genotyping using primers flanking the deleted region. Positive clone \#5 (hereafter named CRISPR- $\beta 2 A d-L Y 5$ cells) was selected.

Cell culture. HEK293T is the cell line in which BRET-based biosensors have been developed in Dr Bouvier's laboratory and this cell line was used for all the BRET and FACS experiments. HEK293SL are a subclone derived from regular HEK293 cells (Ad5 transformed) and were selected in Dr Laporte's laboratory. These cells have a cobblestone appearance and a better adherence as compared with regular HEK293T cells, making them more amenable to microscopy. HeLa is a cell line expressing a higher level of native TfR, compared to HEK293T cells, and were consequently used for monitoring TfR expression by FACS. HEK293T, HEK293SL and HeLa cells were cultured in DMEM supplemented with 10\% FBS, 100 units per $\mathrm{ml}$ penicillin and streptomycin and incubated at $37^{\circ} \mathrm{C}$ in $5 \% \mathrm{CO}_{2}$

Primary rat aortic VSMCs were a gift from Dr. Marc Servant (Université de Montreal) and were used for endogenous AT1R internalization assay. These cells were grown in DMEM/high glucose supplemented with sodium pyruvate, $10 \%$ FBS, and $20 \mu \mathrm{g} \mathrm{ml}^{-1}$ gentamycin.

All cells were regularly tested for mycoplasma contamination (PCR Mycoplasma Detection kit, abm, BC, Canada).

Bioluminescence resonance energy transfer (BRET) assays. HEK293T cells stably expressing $\beta 2$-adaptin-YFP (ref. 24) were cultured as aforementioned with the addition of G418 in the supplemented DMEM. Forty-eight hours before the experiments, $10 \mu \mathrm{g}$ of total DNA (adjusted with salmon sperm DNA) was used to transfect $6 \times 10^{6}$ cells per $\mathrm{ml}$ in $10-\mathrm{cm}$ dishes using $25-\mathrm{kDa}$ linear PEI as a transfecting agent (3:1 PEI/DNA ratio). Cells stably expressing $\beta 2$-adaptin-YFP were transfected with either $250 \mathrm{ng}$ of V2R, or $2.5 \mu \mathrm{g}$ of $\beta 2 \mathrm{AR}$, or $3.0 \mu \mathrm{g}$ of AT1R and with either $100 \mathrm{ng}$ of $\beta$-arrestin1-RlucII or $\beta$-arrestin2-RlucII for the compounds screen, the concentration-response curves, the one-point stimulation experiments, as well as for the kinetics that monitors the interaction between $\beta 2$-adaptin and $\beta$-arrestin. To monitor $\beta$-arrestin recruitment to either V2R or $\beta 2 \mathrm{AR}$, HEK293T cells were transfected with $5 \mu \mathrm{g}$ of V2R-YFP or $3 \mu \mathrm{g}$ of $\beta 2 \mathrm{AR}-\mathrm{YFP}$ and $500 \mathrm{ng}$ of $\beta$-arrestin1-RLucII or $120 \mathrm{ng}$ of $\beta$-arrestin2-RLucII. For the prescreen experiment assessing compounds interference with BRET signals, HEK293T cells were transfected with $100 \mathrm{ng}$ of $\beta$-arrestin1-RlucII. On the day of the BRET experiment, cells were washed, detached and resuspended in Tyrode's buffer. Cells $\left(10^{5}\right.$ cells per well) were distributed in 96-wells microplates. DMSO or compounds selected from the virtual screening were preincubated for $30 \mathrm{~min}$ at indicated concentrations, always keeping DMSO at $1 \%$ final concentration in each well. Cells were treated with AVP or ISO at the indicated times and concentrations, at room temperature. Coelenterazine H (for YFP BRET acceptor) or coelenterazine $400 \mathrm{~A}$ (for GFP10 BRET acceptor) was added at a final concentration of $2.5 \mu \mathrm{M}$ five minutes before measurements. Readings were collected with a Mithras LB 940 multidetector plate reader (Berthold Technologies) to integrate signals detected in the $485 / 20 \mathrm{~nm}$ and $530 / 25 \mathrm{~nm}$ windows for the Renilla luciferase (RlucII) and YFP light emissions, respectively, and in the $400 / 70 \mathrm{~nm}$ and $515 / 25 \mathrm{~nm}$ windows for the RlucII and GFP10 light emissions, respectively. The BRET signal was determined by calculating the ratio of the light intensity emitted by the YFP or GFP10 over the light intensity emitted by the RlucII. Net BRET values were obtained by subtracting the background BRET signals detected when RlucII was expressed alone. Ligand- promoted BRET was calculated by subtracting the BRET ratio obtained in the absence of agonist from the BRET ratio detected in its presence.

BRET imaging. HEK293SL cells seeded on poly-d-lysine-coated glass-bottom 35 -mm culture dishes were transfected with 100 to $200 \mathrm{ng}$ per dish of AT1R-RlucII or V2R-RlucII, respectively, with either $400 \mathrm{ng}$ per dish of rGFP-CAAX or $300 \mathrm{ng}$ per dish of rGFP-FYVE, using X-treme GENE HP reagent (Roche). Two days post transfection, cells were washed once with $1 \mathrm{ml}$ of modified Hank's balanced salt solution $\left(138 \mathrm{mM} \mathrm{NaCl}, 5.33 \mathrm{mM} \mathrm{KCl}, 0.44 \mathrm{mM} \mathrm{KH}_{2} \mathrm{PO} 4,0.33 \mathrm{mM} \mathrm{Na}_{2} \mathrm{HPO}_{4}\right.$, $4.16 \mathrm{mM} \mathrm{NaHCO}_{3}, 1.0 \mathrm{mM} \mathrm{CaCl}, 1.0 \mathrm{mM} \mathrm{MgCl}_{2}, 10 \mathrm{mM}$ HEPES, pH 7.4) and set on the microscope. BRET images were obtained using Nikon Ti-U microscope equipped with $\times 60$ objective (Apochromat TIRF, NA 1.49, Nikon) and EMCCD camera (EM N2 1024, Nüvü Cameras) with filter changer (Lambda 10-2, Sutter instrument). Prolume Purple (final concentration of $10 \mu \mathrm{M}$ ) was added and images were obtained using photon counting feature of the camera. The exposure time of each image was $200 \mathrm{msec}$. Images were obtained with or without a filter corresponding to the BRET acceptor (480LP) wavelength. The filter was switched after taking every 50 images, and the final image was obtained by integrating successive 500 images applying the same filter to the camera. BRET ratio images were generated using pixel arithmetic functions of MetaMorph software version 7.8 (Molecular Devices) as follows: Pixel hue: BRET level calculated by dividing the counts of acceptor luminescence images with total luminescence images, and allocated to default rainbow hue (lowest in purple and highest in red); pixel brightness: the value of donor images with auto brightness.

Protein purification. Plasmid for $\beta 2$-adaptin(700-937)-StrepTagII was transformed in E. coli BL21 pLysS cells that were then grown at $37^{\circ} \mathrm{C}$ in TB medium containing $100 \mathrm{\mu g} \mathrm{ml}^{-1}$ ampicillin and $50 \mathrm{\mu g} \mathrm{ml}^{-1}$ chloramphenicol to an absorbance at $\lambda=600 \mathrm{~nm}$ (A600) of 0.6. Protein expression was induced with $0.2 \mathrm{mM}$ IPTG and cells were grown overnight at $30^{\circ} \mathrm{C}$. Pelleted cells were resuspended in lysis buffer $\left(100 \mathrm{mM}\right.$ Tris- $\mathrm{HCl}, \mathrm{pH} 8.0,150 \mathrm{mM} \mathrm{NaCl}, 1 \mathrm{mg} \mathrm{ml}^{-1}$ lysozyme, $5 \%$ glycerol, PMSF $0.5 \mathrm{mM}$, TCEP $50 \mu \mathrm{M}$ and $1 \mathrm{mM}$ EDTA) and frozen at $-80^{\circ} \mathrm{C}$. For purification, cells were thawed and lysed by mild sonication. After cell debris removal by centrifugation, lysates were incubated with rinsed Strep-Tactin Sepharose beads (IBA) at $4{ }^{\circ} \mathrm{C}$ for one hour on a rotator. The protein was subsequently eluted and purified further by passage over a sepharose column (Bio-Rad) and a gel filtration column. Protein was snap frozen in liquid nitrogen and stored at $-80^{\circ} \mathrm{C}$ for long-term storage.

Differential scanning fluorimetry assay. The thermal denaturation of $\beta 2$-adaptin (residues 700-937, molecular weight $26.88 \mathrm{kDa}$ ) was monitored by CPM (7-Diethylamino-3-(4'-Maleimidylphenyl)-4-Methylcoumarin) dye fluorescence changes upon conjugation to the cysteines of $\beta 2$-adaptin that become exposed upon unfolding. The amount of $2.1 \mu \mathrm{g}$ purified $\beta 2$-adaptin was diluted in $100 \mu \mathrm{l}$ final volume using phosphate buffered saline (PBS) to the concentration of $0.78 \mu \mathrm{M}$. Samples containing $0.5 \mathrm{mM}$ Triton X-100 were incubated for $30 \mathrm{~min}$ without Barbadin (DMSO), with $10 \mu \mathrm{M}, 33 \mu \mathrm{M}$ or $100 \mu \mathrm{M}$ Barbadin, or with $20 \mu \mathrm{M}$ $\beta$-arrestin1 C-terminal peptide (sequence: DDDIVFEDFARQRLKGMKDD), synthesized by Genscript, USA) before the addition of CPM dye (ThermoFisher Scientific, Switzerland). CPM dye of $3 \mathrm{mg} \mathrm{ml}^{-1}$ in DMSO was diluted 1:80 in PBS and $10 \mu \mathrm{l}$ of the dilution was added to each sample to a final concentration of $9.3 \mu \mathrm{M}$. Each sample was split into three $25 \mu \mathrm{l}$ aliquots. The samples were then heated from $30^{\circ} \mathrm{C}$ to $90^{\circ} \mathrm{C}$ at $6{ }^{\circ} \mathrm{C} \mathrm{min}{ }^{-1}$ in a RotorGeneQ and the fluorescence of the CPM dye was monitored using $365 \mathrm{~nm}$ excitation and $460 \mathrm{~nm}$ emission. RotorGeneQ Series Software was used for data analysis. The first derivative of the fluorescence data was used to determine the melting temperatures.

Flow-cytometry for assessing receptor cell surface expression. For monitoring V2R and $32 A R$ cell surface expression, HEK293T cells stably expressing either HA-V2R-Venus or HA- $32 A R-V e n u s$ were seeded in $150 \mathrm{~mm}$ dishes. For monitoring $\mathrm{ET}_{\mathrm{A}} \mathrm{R}$ cell surface expression, HEK293T cells were transfected with $\mathrm{HA}_{\mathrm{E}} \mathrm{ET}_{\mathrm{A}} \mathrm{R}$ in $100 \mathrm{~mm}$ dishes, using the PEI procedure previously described in the methods. Forty-eight hours later, cells were harvested, rinsed with PBS, then detached and resuspended in Tyrode's buffer. Cells $\left(1 \times 10^{6}\right.$ cells per well) were distributed in v-bottom 96-well plates. DMSO, Barbadin $(100 \mu \mathrm{M})$, Pitstop2 $(100 \mu \mathrm{M})$ and Dyngo-3a $(30 \mu \mathrm{M})$ were preincubated for $30 \mathrm{~min}$ (final $1 \%$ DMSO content in each well). Cells were treated at room temperature, in the absence or presence of AVP $(100 \mathrm{nM})$, ISO $(10 \mu \mathrm{M})$ or ET1 $(10 \mathrm{nM})$ for the indicated times then put on ice for the rest of the experiment. Plates were quickly spun at $4^{\circ} \mathrm{C}$ and supernatant from each well was removed using a vacuum line. Cells were resuspended in Tyrode supplemented with 1\% BSA (Tyrode/BSA) containing mouse monoclonal anti-HA antibody $(1: 1,000)$ to label cell surface receptors. After $20 \mathrm{~min}$ incubation, plates were quickly spun then resuspended in Tyrode/BSA containing anti-mouse Alexa Fluor 647 secondary antibody $(1: 1,000)$. After 30 min incubation and protected from light, plates were quickly spun, and cells washed and resuspended in Tyrode and kept on ice. Cells were analysed through a LSR II flow cytometer set to detect YFP and Alexa Fluor $647 \mathrm{~nm}$ in distinct channels (Supplementary Fig. 8). For monitoring transferrin receptor surface expression, HeLa cells were seeded in a $150 \mathrm{~mm}$ dish and incubated for $48 \mathrm{~h}$ before being 
processed. One hour before the experiment, cells were serum-starved, then rinsed with PBS and resuspended in Tyrode's buffer. Cells were distributed in centrifuge tubes $\left(500 \mu \mathrm{l}\right.$ of resuspension per tube with $1 \times 10^{6}$ cells each). DMSO, Barbadin $(100 \mu \mathrm{M})$ or Pitstop $2(100 \mu \mathrm{M})$ were preincubated for $30 \mathrm{~min}$ at room temperature, then cells were put on ice for $10 \mathrm{~min}$. Cells were incubated with Alexa Fluor 633-conjugated transferrin $\left(100 \mu \mathrm{g} \mathrm{ml}^{-1}\right)$ for $30 \mathrm{~min}$ at $4^{\circ} \mathrm{C}$ in the dark, rinsed with cold PBS and shifted to $37^{\circ} \mathrm{C}$ for $15 \mathrm{~min}$, except for a control tube that was kept on ice. Cells were then pelleted, washed, acid-washed $(0.1 \mathrm{M}$ glycine, $150 \mathrm{mM}$ $\mathrm{NaCl}, \mathrm{pH}$ 3), resuspended in Tyrode containing $1 \% \mathrm{BSA}$ and analysed in a LSR II flow cytometer (Alexa Fluor 647 channel).

VSMC internalization assay. $\left[{ }^{125} \mathrm{I}\right]$-AngII was prepared with the Iodogen method, and specific activity was determined from self-displacement and saturation experiments, as previously described ${ }^{65}$. Receptor internalization was performed as described previously ${ }^{26}$. Briefly, VSMCs were plated at a density of $\sim 7 \times 10^{4}$ cells per well in poly-L-ornithine-coated 24 -well plates. When cells were confluent (24-48 h after plating), they were starved in DMEM with $20 \mathrm{mM}$ HEPES (DMEM-H) for $2 \mathrm{~h}$ before Barbadin treatment. Cells were incubated in either DMSO or Barbadin $(20 \mu \mathrm{M})$ for $30 \mathrm{~min}$ at $37^{\circ} \mathrm{C}$, before adding $\left[{ }^{125} \mathrm{I}\right]$-AngII $\left(0.2 \mathrm{nM}\right.$ in $0.1 \%$ BSA binding buffer) for $15 \mathrm{~min}$ at $37^{\circ} \mathrm{C}$. Binding and internalization of $\left[{ }^{125} \mathrm{I}\right]$-AngII was terminated by rapidly rinsing the cells twice with ice-cold PBS and then either rinsing once with ice-cold PBS to obtain total binding, or with $50 \mathrm{mM}$ acetic acid in $150 \mathrm{mM} \mathrm{NaCl}$ (pH 2.7) for $10 \mathrm{~min}$ to determine the internalized receptors (acid-resistant). Cells were solubilized in $0.5 \mathrm{M}$ $\mathrm{NaOH}, 0.05 \%$ SDS and radioactivity was counted using a Wizard 1470 automatic $\gamma$-counter. Per cent receptor internalization was calculated from the ratio of acid-resistant binding over total binding. Non-specific binding was determined in the presence of $1 \mu \mathrm{M}$ unlabelled AngII.

Fluorescence microscopy. For $\beta$-arrestin colocalization with $\beta 2$-adaptin experiments, HEK293T stably expressing human V2R cells were seeded in $35 \mathrm{~mm}$ optical glass-bottom culture dishes with poly-L-lysine. Twenty-four hours later, cells were transfected with $300 \mathrm{ng}$ of $\beta$-arrestin2-mCherry, $400 \mathrm{ng}$ of $\beta 2$-adaptin-YFP with pcDNA3.1 for up to $12 \mu \mathrm{g}$ of total DNA using conventional calcium phosphate co-precipitation method. For colocalization of $\beta$-arrestin2 with $\beta 2$-adaptin and clathrin, CRISPR- $\beta 2$ Ad-LY5 cells were seeded on coverslips coated with poly-Ornithine and transfected with $2 \mu \mathrm{g}$ of HA-V2R, $400 \mathrm{ng}$ of $\beta 2$-adaptinCFP, $300 \mathrm{ng}$ of $\beta$-arrestin2-mCherry, $150 \mathrm{ng}$ of clathrin-YFP and pcDNA3.1 for up to $12 \mu \mathrm{g}$ of total DNA using lipofectamine 2000 according to the manufacturer's instructions. Media were changed the next day and experiment performed $48 \mathrm{~h}$ post transfection. Cells were serum-starved for $30 \mathrm{~min}$, then pretreated with $10 \mu \mathrm{M}$ Barbadin or vehicle (DMSO) for an additional $30 \mathrm{~min}$ before stimulation with $1 \mu \mathrm{M}$ AVP for $2.5 \mathrm{~min}$. Before mounting coverslips on slides, cells were first washed in PBS, then incubated for $10 \mathrm{~min}$ in PBS-containing 4\% Paraformaldehyde (PFA, $\mathrm{v} / \mathrm{v})$. Images of live cells were collected on a Zeiss LSM-510 Meta laser scanning microscope with a $\times 63 / 1.4$ oil objective lens using excitation/emission filter sets: $543 \mathrm{~nm} / 560 \mathrm{~nm}$ (Long Pass) for mRFP, and $514 \mathrm{~nm} / 530-600 \mathrm{~nm}$ (Band Pass) for YFP. Images of fixed cells were collected on a Zeiss LSM-780-NLO laser scanning microscope with a $\times 63 / 1.4$ oil DIC M27 objective lens using $543 \mathrm{~nm}, 514 \mathrm{~nm}$ and $458 \mathrm{~nm}$ for mCherry, YFP and CFP excitation, and a GaAsP spectrum detector set at $588-695 \mathrm{~nm}, 517-580 \mathrm{~nm}$ and $464-517 \mathrm{~nm}$, respectively. Co-localization analysis was performed using regions of interest (ROI) and analysed using Zen software.

GST-pulldown assays. Plasmid DNA for GST and GST- $\beta 2$-adaptin(592-937) were transformed in E. coli BL21 cells. Overnight cultures were grown in superbroth medium supplemented with ampicillin $\left(100 \mu \mathrm{g} \mathrm{ml}^{-1}\right)$, diluted to an $A_{600}$ of 0.4 in the same medium and grown for another $1 \mathrm{~h} 30$ at $37^{\circ} \mathrm{C}$ to reach an $A_{600}$ of 0.8 (log phase). Cultured cells were then induced with $0.1 \mathrm{mM}$ isopropyl-1-thio- $\beta$ D-galactopyranoside (IPTG) for $5 \mathrm{~h}$ at $30^{\circ} \mathrm{C}$. Cells were then pelleted, washed once with PBS and resuspended in PBS containing $1 \mathrm{mM}$ phenylmethylsulfonyl fluoride (PMSF), $2 \mathrm{mg} \mathrm{ml}^{-1}$ lysozyme and incubated for $15 \mathrm{~min}$ on ice. Cells were lysed by immediately adding Triton X-100 (1\% v/v) followed by two freeze-thaw cycles in liquid nitrogen. Solubilized cells were sonicated $(3 \times 15 \mathrm{~s})$ on ice and centrifuged at 13,000 r.p.m. for $10 \mathrm{~min}$. Glutathione-sepharose beads were added to the supernatant and gently shaken at $4^{\circ} \mathrm{C}$ for $2 \mathrm{~h}$. Beads were washed three times with cold PBS containing 1\% Triton X-100, then three times with cold PBS. Protein concentration was determined using a detergent compatible protein assay kit, and the integrity of the fusion proteins was analysed by SDS-polyacrylamide gel electrophoresis and by Coomassie staining. To prepare cell lysate, HEK293T $\left(1.2 \times 10^{6}\right)$ were plated in $100 \mathrm{~mm}$ dishes and transfected $24 \mathrm{~h}$ later with $5 \mu \mathrm{g}$ of Flag- $\beta$ arrestin 1 and pcDNA3.1 (to a total of $12 \mu \mathrm{g}$ ) using conventional calcium phosphate co-precipitation method. After overnight incubation, transfection medium was replaced with fresh MEM. Twenty-four hours later, cells were washed with PBS and lysed in a glycerol buffer containing $1 \mathrm{mM}$ PMSF, $25 \mu \mathrm{g} \mathrm{ml}^{-1}$

leupeptin, $2.5 \mu \mathrm{g} \mathrm{ml}^{-1}$ aprotinin and $1 \mathrm{mM}$ pepstatin. Cell lysates were cleared by centrifugation (14,000 r.p.m. for $15 \mathrm{~min}$ ). Seven micrograms of GST or GST- $\beta 2$-adaptin(592-937) were incubated for $1 \mathrm{~h}$ at RT with or without Barbadin $(200 \mu \mathrm{M})$ in $100 \mu \mathrm{l} \mathrm{PBS}$, then $100 \mu \mathrm{l}$ of cell lysate was added and left $2 \mathrm{~h}$ at $4{ }^{\circ} \mathrm{C}$ on a Nutator. Beads were spun and washed five times in glycerol buffer and resuspended in SDS sample buffer (8\% SDS, $25 \mathrm{mM}$ Tris-HCl, pH 6.5, 10\% glycerol, 5\% 2 -mercaptoethanol, $0.003 \%$ bromophenol blue). Proteins were resolved by electrophoresis on a $10 \%$ gel, transferred onto nitrocellulose and analysed by western blot using mouse monoclonal anti-Flag $(1: 1,000)$ and anti-clathrin $(1: 1,000)$ antibodies, or stained with Coomassie blue for GST protein detection.

Co-immunoprecipitation. Co-immunoprecipitation experiments were performed as previously described ${ }^{67}$. Briefly, HEK293SL cells transfected with $3 \mu \mathrm{g}$ V2R and $500 \mathrm{ng}$ of Flag- $\beta$-arrestin2 were serum-starved for $30 \mathrm{~min}$, and then pretreated for 20 min with DMSO or Barbadin $(50 \mu \mathrm{M})$ before stimulation with AVP $(1 \mu \mathrm{M})$ for 2.5 and $5.0 \mathrm{~min}$. Stimulation was stopped by adding dithiobis succinimidyl propionate (DSP) to cells $(2 \mathrm{mM})$. Cells were then washed in $50 \mathrm{mM}$ Tris- $\mathrm{HCl}$ ( $\mathrm{pH} 7.5$ ) and lysed in RIPA buffer (50 mM Tri-HCl, $\mathrm{pH} 7.4,1 \% \mathrm{NP}-40$ (v/v), $0.5 \%$ Na-Deoxycholate (w/v), $0.1 \%$ sodium dodecyl sulfate $(\mathrm{w} / \mathrm{v}), 150 \mathrm{mM} \mathrm{NaCl}, 2 \mathrm{mM}$ EDTA, $50 \mathrm{mM} \mathrm{NaF}$ ). Total cell lysates (TCL) were immunoprecipitated with anti-AP1/2 antibody $(25 \mu \mathrm{g})$ and then analysed by western blot using anti-adaptin (BD Biosciences, 1:1,000) for TCL and AP1/2 (1:1,000) for IP samples, anti-epsin $(1: 500)$ or anti-Flag antibodies $(1: 1,000)$, and secondary HRP antibodies $(1: 7,000)^{61}$. AP1/2 antibody has been reported to detect both the $\beta 1$ and $\beta 2$ subunits, which have different sizes. However, in HEK293SL, AP1/2 antibody mainly immunoprecipitated and recognized a protein of $\sim 105 \mathrm{kDa}$

(Supplementary Fig. 9), which we validated to be immune-reactive for $\beta 2$-adaptin using a specific antibody against this subunit (BD Bioscience). This was confirmed using $\beta 2$-adaptin knock out cells (CRISPR- $\beta 2$ Ad-LY5, Supplementary Fig. 7).

cAMP assay. Intracellular cAMP accumulation was measured using the cAMP dynamic-2 kit, a competitive immunoassay based on homogeneous time-resolved fluorescence technology. HEK293T cells, as well as HEK293T stably expressing either V2R or $\beta 2 \mathrm{AR}$ were starved for $4 \mathrm{~h}$ in DMEM before being processed. Cells were rinsed once in PBS and once in cAMP-assay buffer (PBS with 1\% BSA and $0.5 \mathrm{mM}$ IBMX), detached and resuspended in the same buffer, then seeded $\left(4 \times 10^{4}\right.$ cells per well) in 96-well microplates. For concentration-response curves, cells were pretreated or not (DMSO) with Barbadin at the indicated concentrations for $30 \mathrm{~min}$ (1\% DMSO final concentration in each well), then treated at room temperature with vehicle, AVP $(100 \mathrm{nM})$, ISO $(1 \mu \mathrm{M})$ or forskolin $(10 \mu \mathrm{M})$ for $15 \mathrm{~min}$ and put at $-80^{\circ} \mathrm{C}$ for $1 \mathrm{~h}$. For kinetics experiments, cells were pretreated or not (DMSO) with Barbadin $(50 \mu \mathrm{M})$ for $30 \mathrm{~min}$, then treated with vehicle, AVP $(100 \mathrm{nM})$ or ISO $(1 \mu \mathrm{M})$ for the indicated times, and put at $-80^{\circ} \mathrm{C}$ for $1 \mathrm{~h}$. Once thawed, cells $\left(4 \times 10^{3}\right.$ cells per well) were transferred in 384-well plates and incubated with cAMP labelled with the dye $\mathrm{d} 2$, and anti-cAMP antibody labelled with Cryptate according to the manufacturer's protocol. Reading of the homogeneous time-resolved fluorescence signal was performed on an Artemis plate reader.

ERK1/2 activation assay. HEK293T cells $\left(10^{5}\right.$ cells per well) were seeded in a 6-well plate and transfected with a V2R encoding plasmid. Forty-eight hours post transfection, cells were serum-starved for $30 \mathrm{~min}$ in MEM containing $20 \mathrm{mM}$ HEPES, treated with either DMSO or Barbadin $(50 \mu \mathrm{M})$ for $10 \mathrm{~min}$, and then stimulated with vehicle (MEM), AVP $(1 \mu \mathrm{M})$ or epidermal growth factor (EGF, $100 \mathrm{ng} \mathrm{ml}^{-1}$ ) for the indicated times. Treatment was stopped on ice with cold PBS, and cells were solubilized in $\times 2$ laemmli buffer $(250 \mathrm{mM}$ Tris- $\mathrm{HCl} \mathrm{pH} 6.8,2 \%$ SDS (w/v), 10\% glycerol (v/v), 0.01\% bromophenol blue (w/v) and 5\% $\beta$-mercaptoethanol $(\mathrm{v} / \mathrm{v}))$. Lysates were resolved on a $10 \%$ SDS-PAGE and analysed by western blot using anti-phospho-ERK1/2 $(1: 1,000)$ and anti-totalERK1/2 (1:2,000). Signals from western blots were determined by densitometry analysis using the Image J software (NIH).

Data and statistical analyses. Nonlinear regression analysis of the concentrationresponse and kinetics curves and statistical analyses (assuming similar variance between groups) were performed with GraphPad Prism software. For the concentration-response curves the 'log inhibitor versus response-three parameters (Hill slope $=-1)^{\prime}$ fitting was used. Student's $t$-test or one-way analysis of variance (ANOVA) and Tuckey's post-hoc tests were performed as appropriate (see figure legends). Two-way ANOVA and Bonferroni's post-hoc tests (comparison between all groups) were used for statistical analysis of western blot signals for ERK and co-immunoprecipitation assays, as well as for compounds' effect on receptor endocytosis kinetics by FACS. Colocalization of signals from microscopy experiments was analysed using Pearson's correlation coefficient.

Data availability. The authors declare that all data supporting the findings in this study are presented within the article and its Supplementary Information files and available from the corresponding author upon request. Amino acid sequences for $\mathrm{h} \beta 2$-adaptin are provided in Supplementary Data 1.

\section{References}

1. Sorkin, A. \& von Zastrow, M. Endocytosis and signalling: intertwining molecular networks. Nat. Rev. Mol. Cell Biol. 10, 609-622 (2009). 
2. Shenoy, S. K. \& Lefkowitz, R. J. Beta-Arrestin-mediated receptor trafficking and signal transduction. Trends Pharmacol. Sci. 32, 521-533 (2011).

3. Lohse, M. J., Benovic, J. L., Codina, J., Caron, M. G. \& Lefkowitz, R. J. Beta-Arrestin: a protein that regulates beta-adrenergic receptor function. Science 248, 1547-1550 (1990).

4. Ferguson, S. S. et al. Role of beta-arrestin in mediating agonist-promoted G protein-coupled receptor internalization. Science 271, 363-366 (1996).

5. Goodman, Jr O. B. et al. Beta-arrestin acts as a clathrin adaptor in endocytosis of the beta2-adrenergic receptor. Nature 383, 447-450 (1996).

6. Laporte, S. A. et al. The beta2-adrenergic receptor/beta-arrestin complex recruits the clathrin adaptor AP-2 during endocytosis. Proc. Natl Acad. Sci. USA 96, 3712-3717 (1999).

7. Oakley, R. H., Laporte, S. A., Holt, J. A., Caron, M. G. \& Barak, L. S. Differential affinities of visual arrestin, beta arrestin1, and beta arrestin2 for G protein-coupled receptors delineate two major classes of receptors. J. Biol. Chem. 275, 17201-17210 (2000).

8. Calebiro, D., Nikolaev, V. O., Persani, L. \& Lohse, M. J. Signaling by internalized G-protein-coupled receptors. Trends Pharmacol. Sci. 31, 221-228 (2010)

9. Irannejad, R. \& von Zastrow, M. GPCR signaling along the endocytic pathway. Curr. Opin. Cell Biol. 27, 109-116 (2014).

10. Lefkowitz, R. J. \& Shenoy, S. K. Transduction of receptor signals by betaarrestins. Science 308, 512-517 (2005).

11. Vilardaga, J. P., Jean-Alphonse, F. G. \& Gardella, T. J. Endosomal generation of cAMP in GPCR signaling. Nat. Chem. Biol. 10, 700-706 (2014).

12. Tsvetanova, N. G., Irannejad, R. \& von Zastrow, M. G protein-coupled receptor (GPCR) signaling via heterotrimeric $\mathrm{G}$ proteins from endosomes. J. Biol. Chem. 290, 6689-6696 (2015).

13. Thomsen, A. R. et al. GPCR-G protein-beta-arrestin super-complex mediates sustained G protein signaling. Cell 166, 907-919 (2016).

14. McMahon, H. T. \& Boucrot, E. Molecular mechanism and physiological functions of clathrin-mediated endocytosis. Nat. Rev. Mol. Cell Biol. 12, 517-533 (2011).

15. Hanyaloglu, A. C. \& von Zastrow, M. Regulation of GPCRs by endocytic membrane trafficking and its potential implications. Annu. Rev. Pharmacol. Toxicol. 48, 537-568 (2008).

16. Gurevich, V. V. \& Gurevich, E. V. The molecular acrobatics of arrestin activation. Trends Pharmacol. Sci. 25, 105-111 (2004).

17. Laporte, S. A., Oakley, R. H., Holt, J. A., Barak, L. S. \& Caron, M. G. The interaction of beta-arrestin with the AP-2 adaptor is required for the clustering of beta(2)-adrenergic receptor into clathrin-coated pits. J. Biol. Chem. 275, 23120-23126 (2000).

18. Scott, M. G., Benmerah, A., Muntaner, O. \& Marullo, S. Recruitment of activated $\mathrm{G}$ protein-coupled receptors to pre-existing clathrin-coated pits in living cells. J. Biol. Chem. 277, 3552-3559 (2002).

19. Laporte, S. A., Miller, W. E., Kim, K. M. \& Caron, M. G. beta-arrestin/AP-2 interaction in $\mathrm{G}$ protein-coupled receptor internalization-identification of a beta-arrestin binding site in beta(2)-adaptin. J. Biol. Chem. 277, 9247-9254 (2002).

20. Schmid, E. M. et al. Role of the AP2 beta-appendage hub in recruiting partners for clathrin-coated vesicle assembly. PLoS Biol. 4, e262 (2006).

21. van der Bliek, A. M. et al. Mutations in human dynamin block an intermediate stage in coated vesicle formation. J. Cell Biol. 122, 553-563 (1993).

22. Krupnick, J. G., Santini, F., Gagnon, A. W., Keen, J. H. \& Benovic, J. L. Modulation of the arrestin-clathrin interaction in cells. Characterization of beta-arrestin dominant-negative mutants. J. Biol. Chem. 272, 32507-32512 (1997).

23. Mundell, S. J., Loudon, R. P. \& Benovic, J. L. Characterization of G protein-coupled receptor regulation in antisense mRNA-expressing cells with reduced arrestin levels. Biochemistry 38, 8723-8732 (1999).

24. Hamdan, F. F. et al. Unraveling G protein-coupled receptor endocytosis pathways using real-time monitoring of agonist-promoted interaction between beta-arrestins and AP-2. J. Biol. Chem. 282, 29089-29100 (2007).

25. Edeling, M. A. et al. Molecular switches involving the AP-2 beta2 appendage regulate endocytic cargo selection and clathrin coat assembly. Dev. Cell 10, 329-342 (2006)

26. Namkung, Y. et al. Monitoring G protein-coupled receptor and beta-arrestin trafficking in live cells using enhanced bystander BRET. Nat. Commun. 7, 12178 (2016).

27. Rene, P. et al. Pharmacological chaperones restore function to MC4R mutants responsible for severe early-onset obesity. J. Pharmacol. Exp. Ther. 335, 520-532 (2010)

28. von Kleist, L. et al. Role of the clathrin terminal domain in regulating coated pit dynamics revealed by small molecule inhibition. Cell 146, 471-484 (2011).

29. Dutta, D., Williamson, C. D., Cole, N. B. \& Donaldson, J. G. Pitstop 2 Is a Potent Inhibitor of Clathrin-Independent Endocytosis. PLoS ONE 7, e45799 (2012).
30. McCluskey, A. et al. Building a better dynasore: the dyngo compounds potently inhibit dynamin and endocytosis. Traffic 14, 1272-1289 (2013).

31. Okamoto, Y., Ninomiya, H., Miwa, S. \& Masaki, T. Cholesterol oxidation switches the internalization pathway of endothelin receptor type A from caveolae to clathrin-coated pits in Chinese hamster ovary cells. J. Biol. Chem. 275, 6439-6446 (2000).

32. Jing, S. Q., Spencer, T., Miller, K., Hopkins, C. \& Trowbridge, I. S. Role of the human transferrin receptor cytoplasmic domain in endocytosis: localization of a specific signal sequence for internalization. J. Cell Biol. 110, 283-294 (1990).

33. Marion, S., Fralish, G. B., Laporte, S., Caron, M. G. \& Barak, L. S. N-terminal tyrosine modulation of the endocytic adaptor function of the beta-arrestins. J. Biol. Chem. 282, 18937-18944 (2007).

34. Krupnick, J. G., Goodman, Jr O. B., Keen, J. H. \& Benovic, J. L. Arrestin/clathrin interaction. Localization of the clathrin binding domain of nonvisual arrestins to the carboxy terminus. J. Biol. Chem. 272, 15011-15016 (1997).

35. Kim, Y. M. \& Benovic, J. L. Differential roles of arrestin-2 interaction with clathrin and adaptor protein 2 in G protein-coupled receptor trafficking. J. Biol. Chem. 277, 30760-30768 (2002).

36. Luttrell, L. M. et al. Activation and targeting of extracellular signal-regulated kinases by $\beta$-arrestin scaffolds. Proc. Natl Acad. Sci. 98, 2449-2454 (2001).

37. Azzi, M. et al. Beta-arrestin-mediated activation of MAPK by inverse agonists reveals distinct active conformations for $\mathrm{G}$ protein-coupled receptors. Proc. Natl Acad. Sci. USA 100, 11406-11411 (2003).

38. Charest, P. G., Oligny-Longpre, G., Bonin, H., Azzi, M. \& Bouvier, M. The V2 vasopressin receptor stimulates ERK1/2 activity independently of heterotrimeric G protein signalling. Cell Signal 19, 32-41 (2007).

39. Luttrell, L. M. \& Gesty-Palmer, D. Beyond desensitization: physiological relevance of arrestin-dependent signaling. Pharmacol. Rev. 62, 305-330 (2010).

40. Gales, C. et al. Probing the activation-promoted structural rearrangements in preassembled receptor-G protein complexes. Nat. Struct. Mol. Biol. 13, 778-786 (2006).

41. Wells, J. A. \& McClendon, C. L. Reaching for high-hanging fruit in drug discovery at protein-protein interfaces. Nature 450, 1001-1009 (2007).

42. Mullard, A. Protein-protein interaction inhibitors get into the groove. Nat. Rev Drug. Discov. 11, 172-174 (2012).

43. Shukla, A. K. et al. Structure of active beta-arrestin-1 bound to a G-protein-coupled receptor phosphopeptide. Nature 497, 137-141 (2013).

44. Aguet, F., Antonescu, C. N., Mettlen, M., Schmid, S. L. \& Danuser, G. Advances in analysis of low signal-to-noise images link dynamin and AP2 to the functions of an endocytic checkpoint. Dev. Cell 26, 279-291 (2013).

45. Krupnick, J. G., Goodman, O. B., Keen, J. H. \& Benovic, J. L. Arrestin/clathrin interaction-Localization of the clathrin binding domain of nonvisual arrestins to the carboxyl terminus. J. Biol. Chem. 272, 15011-15016 (1997).

46. Nesterov, A., Carter, R. E., Sorkina, T., Gill, G. N. \& Sorkin, A. Inhibition of the receptor-binding function of clathrin adaptor protein AP-2 by dominant-negative mutant mu2 subunit and its effects on endocytosis. EMBO J. 18, 2489-2499 (1999).

47. Zimmerman, B. et al. Role of ßarrestins in bradykinin B2 receptor-mediated signalling. Cell. Signal. 23, 648-659 (2011).

48. Eichel, K., Jullie, D. \& von Zastrow, M. beta-Arrestin drives MAP kinase signalling from clathrin-coated structures after GPCR dissociation. Nat. Cell Biol. 18, 303-310 (2016).

49. Lohse, M. J. \& Hofmann, K. P. Spatial and temporal aspects of signaling by G-protein-coupled receptors. Mol. Pharmacol. 88, 572-578 (2015).

50. Ferrandon, S. et al. Sustained cyclic AMP production by parathyroid hormone receptor endocytosis. Nat. Chem. Biol. 5, 734-742 (2009)

51. Irannejad, R. et al. Conformational biosensors reveal GPCR signalling from endosomes. Nature 495, 534-538 (2013).

52. Feinstein, T. N. et al. Noncanonical control of vasopressin receptor type 2 signaling by retromer and arrestin. J. Biol. Chem. 288, 27849-27860 (2013).

53. Lyga, S. et al. Persistent cAMP signaling by internalized LH receptors in ovarian follicles. Endocrinology 157, 1613-1621 2015-1945 (2016).

54. Calebiro, D. et al. Persistent cAMP-signals triggered by internalized G-protein-coupled receptors. PLoS Biol. 7, e1000172 (2009).

55. Kotowski, S. J., Hopf, F. W., Seif, T., Bonci, A. \& von Zastrow, M. Endocytosis promotes rapid dopaminergic signaling. Neuron 71, 278-290 (2011).

56. Merriam, L. A. et al. Pituitary adenylate cyclase 1 receptor internalization and endosomal signaling mediate the pituitary adenylate cyclase activating polypeptide-induced increase in guinea pig cardiac neuron excitability. J. Neurosci. 33, 4614-4622 (2013).

57. Innamorati, G., Sadeghi, H. M., Tran, N. T. \& Birnbaumer, M. A serine cluster prevents recycling of the V2 vasopressin receptor. Proc. Natl Acad. Sci. USA 95, 2222-2226 (1998).

58. Macia, E. et al. Dynasore, a cell-permeable inhibitor of dynamin. Dev. Cell 10, 839-850 (2006) 
59. Hill, T. A. et al. Inhibition of dynamin mediated endocytosis by the dynoles-synthesis and functional activity of a family of indoles. J. Med. Chem. 52, 3762-3773 (2009).

60. Dutta, D. \& Donaldson, J. G. Search for inhibitors of endocytosis: intended specificity and unintended consequences. Cell Logist. 2, 203-208 (2012).

61. Zimmerman, B., Simaan, M., Lee, M. H., Luttrell, L. M. \& Laporte, S. A c-Src-mediated phosphorylation of AP-2 reveals a general mechanism for receptors internalizing through the clathrin pathway. Cell Signal 21, 103-110 (2009).

62. Morris, G. M. et al. AutoDock4 and AutoDockTools4: automated docking with selective receptor flexibility. J. Comput. Chem. 30, 2785-2791 (2009).

63. Terrillon, S. et al. Oxytocin and vasopressin V1a and V2 receptors form constitutive homo- and heterodimers during biosynthesis. Mol. Endocrinol. 17, 677-691 (2003).

64. Freedman, N. J. et al. Phosphorylation and desensitization of human endothelin $A$ and $B$ receptors-evidence for $G$ protein-coupled receptor kinase specificity. J. Biol. Chem. 272, 17734-17743 (1997).

65. Zimmerman, B. et al. Differential beta-arrestin-dependent conformational signaling and cellular responses revealed by angiotensin analogs. Sci. Signal. 5, ra33 (2012).

66. Paradis, J. S. et al. Receptor sequestration in response to beta-arrestin-2 phosphorylation by ERK1/2 governs steady-state levels of GPCR cell-surface expression. Proc. Natl Acad. Sci. USA 112, E5160-E5168 (2015).

67. Khoury, E., Nikolajev, L., Simaan, M., Namkung, Y. \& Laporte, S. A. Differential regulation of endosomal GPCR/beta-arrestin complexes and trafficking by MAPK. J. Biol. Chem. 289, 23302-23317 (2014).

68. Fessart, D. et al. Src-dependent phosphorylation of beta2-adaptin dissociates the beta-arrestin-AP-2 complex. J. Cell Sci. 120, 1723-1732 (2007).

69. Goupil, E. et al. A novel biased allosteric compound inhibitor of parturition selectively impedes the prostaglandin F2 alpha-mediated Rho/ROCK signaling pathway. J. Biol. Chem. 285, 25624-25636 (2010).

70. Ran, F. A. et al. Genome engineering using the CRISPR-Cas9 system. Nat. Protoc. 8, 2281-2308 (2013).

\section{Acknowledgements}

We are grateful to Drs Monique Lagacé, Hervé Enslen and Stefano Marullo for critical reading of the manuscript, and Dr Christian Le Gouill for the set-up of the computer cluster used for this study and for useful discussions and advice. EMCCD camera (EM N2 1024, Nüvü Cameras) was kindly loaned by the Canadian Space Agency. We thank the Molecular Imaging Platform of the Research Institute of the McGill University Health Centre and staff for providing services. At the time of this study, A.B. held postdoctoral fellowships from Groupe de Recherche Universitaire sur le Médicament (GRUM) and Fonds de la Recherche du Québec - Santé (FRQS), B.Z. a Canadian Institutes of Health Research (CIHR) Banting and Best doctoral research award, and E.K. a studentship from the McGill Division of Endocrinology and Metabolism. J.S.P. holds a studentship from the UdeM faculté des études supérieures et postdoctorales. L.Y. holds a postdoctoral internship from Mitacs. This work was supported by CIHR Operating Grants to M.B. (MOP-10501), to S.A.L. (MOP-74603) and to P.P.R. (MOP-123408). M.B. holds a Canada Research Chairs in Signal Transduction and Molecular Pharmacology. At the time of this study, S.A.L. held a Canada Research Chair in Molecular Endocrinology and a senior scholarship from FRQS. P.P.R. is a senior Research Scholar of the FRQS.

\section{Author contributions}

A.B. and M.B. designed the study. A.B. performed the virtual screen, $\beta 2$-adaptin protein purification and cAMP experiments. A.B. and J.S.P. performed BRET and flow-cytometry experiments. B.Z. contributed to the design and execution of biochemical and microscopy experiments. S.A. performed microscopy and pulldown experiments. E.K. performed MAPK assays. J.G. performed BRET and MAPK assays. L.N. performed microscopy experiments. L.Y. performed pulldown experiments and generated the $\beta 2$-adaptin CRISPR cell line. Y.N. performed the internalization assay in VSMCs. H.K. performed the BRET imaging experiments. M.A. contributed in the experimental

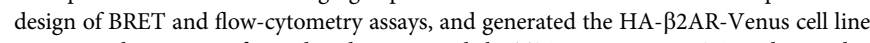
F.M.H. and D.B.V. performed and interpreted the TSA experiments. S.A.L. designed, supervised and interpreted experiments performed in his lab. All the authors analysed the final data. A.B., J.S.P. and M.B. wrote the manuscript, with the assistance of B.Z., P.P.R. and S.A.L.

\section{Additional information}

Supplementary Information accompanies this paper at http://www.nature.com/ naturecommunications

Competing interests: The authors declare no competing financial interests.

Reprints and permission information is available online at http://npg.nature.com/ reprintsandpermissions/

How to cite this article: Beautrait, $\mathrm{A}$ et al. A new inhibitor of the $\beta$-arrestin/AP2 endocytic complex reveals interplay between GPCR internalization and signalling. Nat. Commun. 8, 15054 doi: 10.1038/ncomms15054 (2017).

Publisher's note: Springer Nature remains neutral with regard to jurisdictional claims in published maps and institutional affiliations.

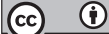

This work is licensed under a Creative Commons Attribution 4.0 International License. The images or other third party material in this article are included in the article's Creative Commons license, unless indicated otherwise in the credit line; if the material is not included under the Creative Commons license, users will need to obtain permission from the license holder to reproduce the material To view a copy of this license, visit http://creativecommons.org/licenses/by/4.0/

(C) The Author(s) 2017 